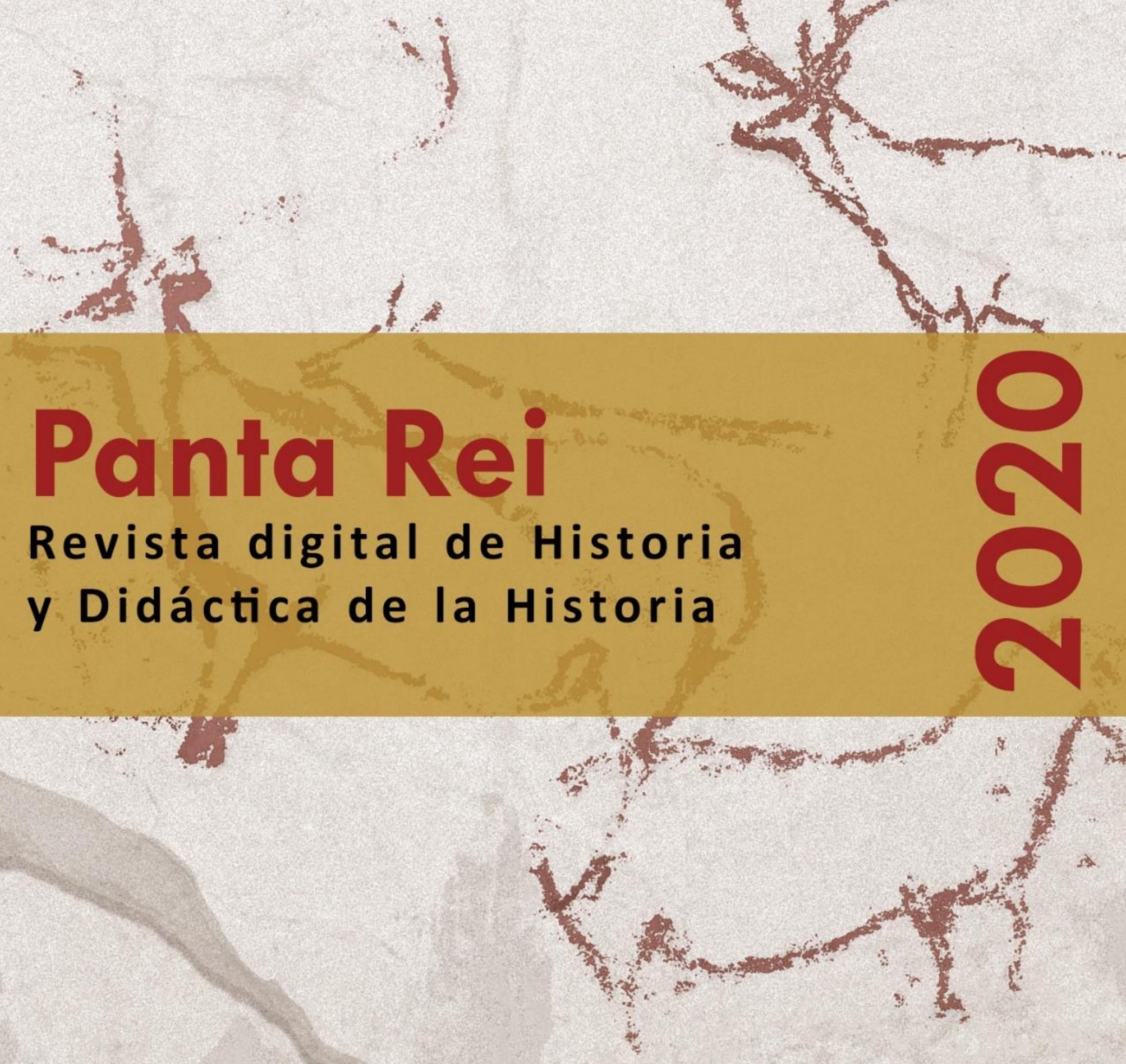




\section{0}

Revista anual

Fecha de inicio: 1995

RevistaPantaRei.pantarei@um.es

\section{Edita:}

Centro de Estudios del Próximo Oriente y la

Antigüedad Tardía - CEPOAT

Edificio Universitario Saavedra Fajardo.

Universidad de Murcia

C/ Actor Isidoro Máiquez, 9

30007 - MURCIA - ESPAÑA

Teléfono: $(+34) 868883890$

cepoat@um.es

Web: www.um.es/cepoat/pantarei

Ediciones de la Universidad de Murcia - EDITUM

Edificio Pleiades. Campus de Espinardo.

Universidad de Murcia

$\mathrm{C} /$ Campus, s/n

30100 - MURCIA - ESPAÑA

Teléfono: $(+34) 868883013$

En portada: calco de las pinturas rupestres de la editum@um.es

Web: https://www.um.es/web/editum/

Cueva del Niño. García Moreno et al., 2016.

Edición 2020

ISSNe: 2386-8864

Responsables de los textos: sus autores.

ISSN: $1136-2464$

Depósito legal: MU-966-1995

Responsable de la presente edición: Consejo Editorial de Panta Rei. 


\section{CONSEJO DE REDACCIÓN}

Coordinador editorial

Egea Vivancos, Alejandro [Didáctica de las Ciencias Sociales, Universidad de Murcia]

Secretaria

Arias Ferrer, Laura [Didáctica de las Ciencias

Sociales, Universidad de Murcia]

Editores

Jiménez Vialás, Helena [Historia Antigua, Universidad de Murcia]

Martínez Gil, Tània [Didáctica de las Ciencias

Sociales, Universidad de Barcelona]

Meseguer Gil, Antonio José [Historiador, Profesor de

Secundaria]

Ortiz García, Jónatan [Arqueología, Universidad de

Alcalá de Henares]

Romero Molero, Alberto [Arqueología, Universidad

Isabel I]

Sáez Giménez, David Omar [Historiador, Profesor

de Secundaria]

Sáez Rosenkranz, Isidora V. [Didáctica de las

Ciencias Sociales, Universidad de Barcelona]

Sánchez Mondejar, Celso Miguel [Arqueólogo,

Patrimonio Inteligente]

Responsable informático

Martínez García, José Javier [CEPOAT, Universidad de Murcia]

Responsables de traducción y corrección lingüística Martínez Martínez, Cristina [Profesora de Secundaria, Sociedad Española de Lenguas Modernas] Albaladejo Albaladejo, Sara [ISEN-Universidad de Murcia]

\section{CONSEJO ASESOR}

Adroher Auroux, Andrés María [Arqueología, Universidad de Granada]

Albero Muñoz, $M^{a}$ del Mar [H. ${ }^{a}$ del Arte, Universidad de Murcia]

Alia Miranda, Francisco [Historia Contemporánea, UCLM]

Arciniega García, Luis [Historia del Arte, Universidad de Valencia]

Barrio Barrio, Juan Antonio [Historia Medieval,

Universidad de Alicante]

Castellano i Solé, Núria [Egiptología, Schola

Didàctica Activa S.L.]

Chapman, Arthur [History Education, University

College of London, Reino Unido]

Cid López, Rosa María [Historia Antigua, Universidad de Oviedo]

Cobacho López, Ángel [Derecho, Universidad de Murcia]

Cuenca López, José María [Didáctica de las Ciencias Sociales, Universidad de Huelva]
Egea Bruno, Pedro M. ${ }^{a}$ [Historia Contemporánea, Universidad de Murcia]

Feijoo Martínez, Santiago [Arqueología, Consorcio

Ciudad Monumental de Mérida]

García Atienzar, Gabriel [Prehistoria, Universidad de

Alicante]

Ginestí Rosell, Anna [Filología Clásica, Katholische

Universität Eichstätt-Ingolstadt]

González Monfort, Neus [Didáctica de las

Ciencias Sociales, Universidad Autónoma de

Barcelona]

González Soutelo, Silvia [Arqueología, Universidad de Vigo]

Haber Uriarte, María [Prehistoria, Universidad de Murcia]

Hernández de la Fuente, David [Filología Clásica, Universidad Complutense]

Hutson, Scott R. [Anthropology, University of Kentucky, EEUU]

Igual Luis, David [Historia Medieval, UCLM]

Irigoyen López, Antonio [Historia Moderna,

Universidad de Murcia]

Jover Maestre, Francisco Javier [Prehistoria,

Universidad de Alicante]

Mahony, Simon [Digital Humanities, University College of London, Reino Unido]

Marsilla de Pascual, Francisco Reyes [Técnicas

historiográficas, Universidad de Murcia]

Martínez-Burgos García, Palma [H. ${ }^{a}$ del Arte, UCLM]

Mathis, Christian [Didaktik der Geschichte, PH Zürich]

Miralles Maldonado, José Carlos [Filología Clásica,

Universidad de Murcia]

Molina Gómez, José Antonio [Historia Antigua,

Universidad de Murcia]

Mónica Ghirardi [Historia Moderna, Universidad

Nacional de Córdoba, Argentina]

Navarro Espinach, Germán [Historia Medieval,

Universidad de Zaragoza]

Noguera Celdrán, José Miguel [Arqueología,

Universidad de Murcia]

Ortiz Heras, Manuel [Historia Contemporánea, UCLM]

Panzram, Sabine [Historia Antigua, Universität

Hamburg]

Pérez Molina, Miguel Emilio [Filología Clásica,

Universidad de Murcia]

Prados Martínez, Fernando [Arqueología,

Universidad de Alicante]

Sánchez lbáñez, Raquel [Didáctica de las Ciencias

Sociales, Universidad de Murcia]

Sancho Gómez, Miguel Pablo [Educación, UCAM]

Victoria Moreno, Diego [Historia Contemporánea,

UNED]

Vilar García, María José [Historia Contemporánea,

Universidad de Murcia]

Vivas Sainz, Inmaculada [H. ${ }^{a}$ del Arte, UNED]

Zamora López, José Ángel [Próximo Oriente Antiguo,

CCHS-CSIC] 



\section{Índice}

\section{Artículos}

Las ocupaciones paleolíticas en el sur de la provincia de Albacete

Noelia Sánchez Martínez

El elefante en las acuñaciones hispanocartaginesas

José Luis Aledo Martínez

La epigrafía votiva romana de Caldas de Montbui (Vallés Oriental, Barcelona) (ss. I-II d. C.). Un ejemplo de promoción de las élites provinciales de la tarraconensis en centros de aguas mineromedicinales

Jesús Sánchez Alguacil

Representación de la historia de España por medio de la filatelia. Estudio de los sellos diseñados por Gallego y Rey

Pedro Vázquez-Miraz

La representación del patrimonio arqueológico en los libros de texto de Educación Primaria: EI 109 contexto indígena canario como estudio de caso

A. José Farrujía, Carmen Ascanio Sánchez, Ulises Martín Herández y Cristo Manuel Hernández Gómez

La empatía como elemento para la adquisición del pensamiento histórico en alumnos de 129 bachillerato. Un estudio de caso centrado en la Guerra Civil española y el franquismo Sebastián Molina Puche y Adrián Salmerón Ayala

Fuentes orales para el desarrollo de la empatía histórica: un estudio en la formación del 155 profesorado de Educación Infantil

$M^{a}$. Teresa Carril-Merino, Beatriz Andreu-Mediero, Mercedes de la Calle Carrecedo y Esther López Torres

¿Qué aporta el género a la formación de docentes de historia? La valoración de la perspectiva de género entre los estudiantes del Máster de Profesor/Profesora en Educación Secundaria Helena Rausell Guillot

Educar para una ciudadanía crítica: una investigación a partir de los usos y finalidades de la historia escolar

Néstor Banderas Navarro

\section{Reseñas}

A. Brilli (2018). El viaje a Oriente, Madrid: A. Machado Libros, 390 págs Juan Álvarez García

Altamira (Hugh Hudson, 2016) 



\title{
Educar para una ciudadanía crítica: una investigación a partir de los usos y finalidades de la historia escolar
}

\author{
Teaching for a Critical Citizenship: a Research Based on the Uses and \\ Purposes of School History
}

\author{
Néstor Banderas Navarro \\ Universitat de València \\ nestor.banderas@uv.es \\ 0000-0001-8807-1919
}

Recibido: $28 / 09 / 2019$

Aceptado: 17/04/2020

\section{Resumen}

En esta investigación se examinan los usos y finalidades de la historia en un instituto en relación a la formación ciudadana. El saber histórico tiene gran potencial crítico y permite adquirir criterios para actuar democráticamente. Se emplearán entrevistas semiestructuradas a dos docentes y cuestionarios y narrativas a su alumnado de $1 .^{\circ}$ y $4 .^{\circ}$ ESO. La investigación constata un posicionamiento docente híbrido, encontrando rasgos de modelos tradicionales en la enseñanza (el escaso tratamiento de temas controversiales), y críticos, como la creencia en el potencial transformador de la materia. En el alumnado se observarán posiciones objetivistas acerca del pasado, que conviven con ejemplos de mayor capacidad de agencia ante cuestiones actuales. La profundización en estrategias didácticas que aborden la educación política desde la historia redundará en la adquisición de habilidades y actitudes para vivir en democracia.

\section{Palabras clave}

Civismo, Modelos de enseñanza, Profesorado de instituto, Política, Currículo.

\section{Abstract}

This research examines the uses and purposes of history in a high school in relation to citizen training. Historical knowledge has great criticism potential and allows acquiring criteria to act democratically. Semi-structured interviews with two teachers and questionnaires and narratives will be used for students in $1^{\text {st }}$ and $4^{\text {th }}$ ESO. The research shows a hybrid teaching position, finding traits of traditional models in teaching (the scarce treatment of controversial topics), and critics, such as the belief in the transformative potential of the subject. In the students, objectivist positions about the past will be observed, which coexist with examples of greater agency capacity in the face of current issues. The deepening of didactic strategies that address political education from History will result in the acquisition of skills and attitudes to live in democracy.

\section{Keywords}

Civics, Teaching Models, High school teachers, Politics, Curriculum. 


\section{Planteamiento de la investigación}

La Educación Secundaria Obligatoria constituye una etapa de enseñanza en la que el alumnado debe desarrollar unos aprendizajes considerados básicos para la ciudadanía hasta los dieciséis años. Este alumnado está en un momento clave para formar su carácter, sus habilidades sociales y su capacidad para desenvolverse en sociedad. Diferentes autores han observado en la adolescencia un escaso compromiso ciudadano (Franklin, 2004; Saha, Print y Edwards, 2007), algo que Funes (2006) concretó señalando una serie de notas características de la ciudadanía juvenil: la desconfianza hacia las instituciones convencionales y los partidos, el escaso interés por la política, así como las identidades difusas en esta materia. Si bien tomar el pulso del interés de los adolescentes hacia la vida política resulta, cuando menos, complicado en algunos estudios se ha comenzado a ver un crecimiento del interés hacia la política por parte de los jóvenes en la última década. Algunos estudios (Díaz-Chorne y Díaz-Catalán, 2016) han señalado, atendiendo a eurobarómetros y a informes elaborados en el marco de la Unión Europea, que no hay una desafección política generalizada en la juventud, algo que se comprueba por la participación en organizaciones juveniles, en el voluntariado o en la expresión de opiniones políticas en las redes sociales de un modo creciente. Se ha constatado en los últimos años un crecimiento en la sensibilización hacia temas como la desigualdad o el cambio climático (Parés y Subirats, 2016), comprobándose un descenso en el porcentaje de jóvenes escasamente interesados por la política (Injuve, 2017). Por tanto, es evidente que esta participación política informal, de carácter sociocéntrico (Arias-Cardona y Alvarado, 2015), va más allá de la concepción formal sobre la política que se ha centrado tradicionalmente en la afiliación, el voto y la orientación política.

A pesar de que las estadísticas parecen avalar la idea de que los jóvenes no son totalmente ajenos a la política, es cierto que persisten importantes límites en cuanto a la comprensión de qué es la política y las dimensiones participativas en ella. El Informe Juventud en España de 2016, elaborado por el INJUVE, incluyó una pregunta realizada a 5.002 estudiantes ("¿Qué es en lo primero que suelen pensar cuando oyen la palabra política?"). En ella se obtuvo un $43,1 \%$ de respuestas que coincidían en pensar en los partidos políticos y el juego parlamentario, un $23,2 \%$ en el gobierno y el Estado y solo un $19,6 \%$ en la vida política de los ciudadanos de manera global. Esta última cifra permite afirmar que buena parte de los jóvenes encuestados posee una concepción demasiado estricta del significado de la política.

Atendiendo a esta realidad, consideramos que la escuela $y$, de modo muy específico la Historia como materia, tienen un papel clave en la formación política y ciudadana del alumnado (Pagès, 2005). Esta relación ha sido defendida desde diferentes voces que han propugnado una didáctica crítica como método para potenciar esta relación (Cuesta, Mainer y Mateos, 2008), establecer un vínculo inequívoco entre educación histórica y ciudadanía (Haste y Bermúdez, 2017) - contribuir, desde el pensamiento histórico, al aprendizaje de las habilidades democráticas (Heimberg, 2009). Esta concepción acerca de los usos y finalidades de la materia de Historia no ha estado, ni está, generalizada por el conjunto del profesorado dado que, la enseñanza de la Historia siempre ha sido un campo de liza entre diferentes actores sociales e instituciones que han tratado de utilizarla de acuerdo con diferentes finalidades. A grandes rasgos, se han podido evidenciar notables diferencias epistemológicas y metodológicas entre la visión de la Historia escolar como una herramienta para construir un conjunto de identidades sociales y los que la han considerado como un útil instrumento para educar mentes libres. En estas páginas se tratará de poner el punto de mira en dos problemáticas presentes en la educación española y, en concreto, 
en la enseñanza y el aprendizaje de la historia: la preeminencia, aún hoy, de enfoques en la enseñanza del pasado que contribuyen a la reproducción de identidades consideradas incuestionables por la presencia de unas ideas acerca de la Historia de tipo objetivista pretendidamente neutrales; así como la falta de enfoques educativos que formen al alumnado en la práctica de la democracia, vinculándolo a las carencias observadas en los estudios anteriormente mencionados acerca de la visión y representación de la política por parte de los jóvenes.

La escasa formación sociopolítica de los adolescentes actuales se debe a múltiples causas, pero es evidente que la educación tiene un papel capital $y$, en ella, la enseñanza de las materias humanísticas. Nuestra investigación pretende constituir una reflexión acerca del potencial formador en materia política del conocimiento histórico, dado que este tiene un protagonismo esencial en la esfera pública, de acuerdo con las propuestas de Habermas sobre los usos públicos de la Historia (Cuesta, 2011). En todo caso, asumiendo, no obstante, que no es la enseñanza de la Historia la única fuente de conformación de actitudes y prácticas ciudadanas. En momentos como el actual en que los ámbitos de sociabilidad y aprendizaje del alumnado trascienden lo formal, el alcance de la formación histórica en el ámbito de la educación será siempre limitado, si bien puede adquirir un potencial cualitativo evidente al permitir el análisis de las sociedades históricas y actuales y comprender los rasgos del mundo que habitamos. Todo ello debe redundar positivamente en la formación ciudadana, una misión de extrema dificultad (Marí, Moreno e Hipólito, 2016) que debe pautarse y estructurarse por parte del docente dado que, si no se realiza de una manera explícita, no podrá esperarse una transferencia generalizada por parte del alumnado (Levstik, 2014). Por tanto, a lo largo de este trabajo nos planteamos las siguientes preguntas de investigación: ¿QQué ideas tienen las docentes entrevistadas acerca de la utilidad de la Historia escolar en la formación política del alumnado? ¿Qué concepciones desarrolla su alumnado sobre la potencialidad del saber histórico para la educación política?

Para profundizar en las respuestas de esta cuestión hemos partido de dos hipótesis de trabajo:

1. Los discursos de las docentes de Historia entrevistadas acerca de su práctica educativa no se orientan a educar al alumnado en las habilidades y el ejercicio de la democracia mediante el cuestionamiento de las identidades y la transformación del presente.

2. El alumnado, a partir de la muestra seleccionada, mantiene una concepción limitada de la potencialidad del saber histórico en su contribución a la educación política.

Con la finalidad de examinar el cumplimiento, total o parcial, o el descarte de estas hipótesis de trabajo, hemos convenido en programar los siguientes objetivos:

1. Examinar las convicciones de dos docentes actuales mediante una entrevista para comprobar sus concepciones acerca de los usos y finalidades de la Historia escolar en su práctica de aula en relación a la formación ciudadana del alumnado.

2. Conocer las ideas del alumnado de estas docentes acerca de los usos y finalidades de la Historia aprendida y su relación con la construcción de una ciudadanía crítica. 


\section{Marco teórico}

A lo largo de estas páginas pondremos el foco en tres dimensiones referidas a los usos y finalidades de la Historia escolar: la contribución a la conformación y naturalización de identidades colectivas y representaciones sociales; el papel de la disciplina desde el punto de vista competencial y de las destrezas de pensamiento histórico; y el papel de la materia como formadora y constructora de una ciudadanía crítica y políticamente activa. Esta última dimensión se vinculará con el rol del profesorado para profundizar en este objetivo del pensamiento histórico. Valorar la presencia de estas dimensiones en la presente investigación permitirá comprender cómo el conocimiento histórico escolar puede contribuir a la formación de una ciudadanía democrática o, por el contrario, obstaculizar este proceso educacional.

\subsection{La historia como herramienta de reproducción de identidades colectivas}

Uno de los usos y finalidades de la Historia escolar con mayor duración y trascendencia (Peck y Seixas, 2008) ha sido el de contribuir a la reproducción de representaciones sociales de manera acrítica y naturalizada (Jodelet, 2000; Moscovici, 1986). Es decir, el estudio del pasado ha servido para facilitar el aprendizaje, generación tras generación, de conocimientos reconocidos por una comunidad social definida culturalmente: percepciones y opiniones identificadas con el sentido común de la colectividad, difícilmente alterables porque devienen de la suma de experiencias individuales y actúan como estabilizadoras del orden social (Moscovici y Hewstone, 1986). Estas representaciones sociales han constituido a menudo identidades colectivas de diversa naturaleza: nacionales, religiosas, étnicas, políticas o de género, entre otras. No obstante, en esta investigación optamos por centrarnos específicamente en las nacionales y las políticas por tener una estrecha relación con los objetivos planteados, si bien podrán comentarse otros aspectos que surjan en la muestra analizada.

En referencia a las identidades nacionales, el pasado ha sido y es un instrumento para legitimar las naciones, tanto en estadios embrionarios como en momentos de mayor auge y poder. Así lo analizaron Hobsbawm y Ranger (2002), quienes se refirieron a la "invención de la tradición" mediante el análisis de una serie de prácticas y de rituales simbólicos que funcionaron como mecanismos para garantizar la cohesión social en torno a un pasado imaginado (Álvarez, 2017). Investigaciones semejantes del hecho nacional en autores como Benedict Anderson (1993), Michael Billig (1995), Anne-Marie Thiesse (1999) o Miroslav Hroch (2001), han coincidido en afirmar que el pasado y las tradiciones sirven como sostén para configurar un relato compartido que permite, no solo sentirse parte de un ente colectivo, sino también luchar y morir por él.

La educación ha constituido un elemento clave en la construcción nacional; por ello, las tradiciones inventadas han tenido un eco indudable en la educación española desde el siglo XIX, momento en que se configuró el modelo de Historias Generales que sirvió para legitimar el Estado-nación liberal. Este modelo ha estado revestido de un "denso manto de tópicos y lugares comunes" (Romero, 2018, p. 113) y siguiendo las investigaciones de autores como Carretero, Castorina, Sarti, Val Alphen y Barreiro (2013) han tenido como notas comunes la valoración positiva del pasado nacional y de la historia política del país, así como la identificación de una serie de acontecimientos pasados, personajes y héroes nacionales considerados fundacionales en el discurso de la nación. 
Este uso otorgado a la Historia escolar como formadora de patriotas supone uno de los elementos característicos del código disciplinar consolidado a mediados del siglo XIX: un conjunto de características, valores y suposiciones que configuraron esta materia (Cuesta, 1997). El código disciplinar de la Historia tuvo además del nacionalismo, el memorismo, el arcaísmo y el elitismo como elementos propios del modo de educación tradicional-elitista, fundamental durante el ochocientos, así como también durante periodos dictatoriales (Cuesta, 1997). En esta investigación analizaremos, partiendo de los objetivos marcados, de qué manera se asumen de forma acrítica las identidades colectivas y si el alumnado es capaz de concebirlas de modo plural y no esencialista, algo deseable para la construcción de una ciudadanía crítica.

\subsection{La historia enseñada desde el discurso competencial}

Otra forma de concebir la educación histórica es la de considerarla como un conjunto de métodos orientados a la investigación: la concepción de esta disciplina como una oportunidad para el aprendizaje de las técnicas y herramientas de la indagación histórica mediante los contenidos de primer y segundo orden. La finalidad de este modo de enseñar historia no se queda únicamente en el ámbito positivista al dar respuesta a preguntas que dan cuenta del objeto de conocimiento (¿Qué? ¿Quién? ¿Cuándo? ¿Dónde?), sino que tratan de desarrollar destrezas históricas en el alumnado (Gómez y Rodríguez, 2017). Estos conceptos de segundo orden han sido sistematizados desde diferentes voces: por ejemplo, Grant (2018), que señala una serie de habilidades históricas sistematizadas por el National Center for History in the Schools en 1996: el análisis de causas y consecuencias o la comparación de la realidad sociopolítica de diferentes áreas. De un modo semejante, desde el ámbito canadiense, Peter Seixas y Tom Morton (2013) configuraron unas habilidades similares para desarrollar el pensamiento histórico en la escuela, imitando así el proceso de los historiadores para examinar las fuentes históricas.

En relación con lo anterior, el enfoque competencial que se ha implantado en la educación europea y española ha supuesto una oportunidad para desarrollar estas habilidades históricas que, desde un enfoque puramente memorístico, no tendrían lugar. La Recomendación 2006/962/EC, del Parlamento Europeo y del Consejo, de 18 de diciembre de 2006, sobre las competencias clave para el aprendizaje permanente, animó a los Estados comunitarios a implementar una dimensión competencial que combinara los conocimientos con las destrezas, desarrolladas en contextos reales por el alumnado. No obstante, y sin negar las posibilidades de este nuevo marco que la legislación educativa española ha adoptado, se han podido diagnosticar diferentes problemas acerca de este planteamiento en la materia de Historia. Uno de ellos es la generalidad y la insuficiencia de las competencias clave, definidas de un modo global, en su aplicación a la alfabetización histórica (Sáiz, 2013a), así como el predominio de estructuras cerradas y escasamente competenciales en los libros de texto (Bel, Colomer y Valls, 2019; Viñao, 2003). Otro de los problemas es el conjunto de principios economicistas y neoliberales que existen detrás de las competencias. Según autores como Fernández, García y Galindo (2017), el aprendizaje mediante una serie de competencias clave no redundaría en una reflexión crítica sobre el currículum, sino en la incorporación acrítica del alumnado al modelo económico capitalista, que se ve complementado por estrategias de comparación nacional e internacional y un mayor control educativo mediante objetivos de aprendizaje y pruebas estandarizadas (Ydesen y Andreasen, 2019). Supondría, por tanto, concebir el currículum de manera naturalizada sin desentrañar los mecanismos de que dispone este para promover unas actitudes conformistas y acomodaticias al sistema económico imperante (Silva, 2001). 
En estas páginas se tratará de advertir de qué modo se concibe la epistemología de la historia por parte de las docentes, valorando si se adoptan estrategias didácticas competenciales y de qué modo influyen en la educación política del alumnado.

\subsection{La historia: una disciplina crítica y transformadora}

En una tercera dimensión de los usos y finalidades de la materia, la Historia enseñada y aprendida experimenta una relación con el presente, una relación que puede adquirir una función formadora o una función transformadora. En el primer caso, la historia tiene la función de conseguir que el alumnado comprenda los rasgos económicos, sociales, políticos y culturales de las sociedades actuales; un proceso que se detiene en la comprensión profunda de estos rasgos pero que no avanza hacia la previsión o hacia el cuestionamiento, siguiendo las palabras de Febvre (1982). Cuando la historia únicamente sirve para la descripción pasiva del pasado con la finalidad de comprender el presente, esta se sitúa en la "mneme" (Lomas, 2011) y puede acabar cayendo en la legitimación. No obstante, en una segunda dimensión, la Historia escolar adquiere una función transformadora y de recuerdo como acción de búsqueda ("anamnesis"), siguiendo la conceptualización de Carlos Lomas (2011).

La Historia, concebida de forma crítica, tiene por finalidad la educación en valores propios de la ciudadanía y proviene de lo que Carretero, Rosa y González (2006) señalan como la racionalidad crítica de la llustración. Concebir la materia histórica desde este punto de vista es una decisión consciente, que tiene sus bases ideológicas en diversos referentes intelectuales que han tratado de orientarla hacia esta dimensión. Hacia 1916 el estadounidense John Dewey señaló en Democracia y Educación que la Historia debía protagonizar un papel fundamental en la transformación educativa; la consideraba una disciplina con gran potencial para la comprensión y el cuestionamiento del presente. Señalaba Dewey (1995, p. 185) que "estudiada de esta manera, la historia llegaría a ser naturalmente de mucho más valor ético en la enseñanza". Este enfoque, por tanto, viraba desde la concepción del currículo cerrado y con una mera función informadora, hacia el ámbito de la actuación y el compromiso, lo cual permitiría contribuir a la formación política ciudadana desde la educación.

No obstante, fue la pedagogía crítica en el siglo XX la que ofreció una malla conceptual y una serie de reflexiones teóricas sobre las finalidades de la materia, y la que estableció las bases para que, a finales de esta centuria, surgieran de nuevo voces de profesionales de la Historia que enlazaran con este paradigma. Paulo Freire es, quizás, el referente más decisivo por su influencia posterior, autor que criticó la "educación bancaria" (Freire, 1975; 2009) propugnando así una educación problematizadora, una alternativa donde el conocimiento se construye en un proceso complejo en que el alumno interviene de una manera decisiva y no acepta, sin más, "un futuro preestablecido" (Feire, 1975, p. 96), sino que se convierte en un sujeto que cuestiona la realidad.

Siguiendo los referentes de Freire, Michael Apple esbozó el concepto de "intelectual orgánico" con el que propuso referirse al sujeto capaz, ya no de reproducir en la escuela el orden imperante, sino de cuestionario desde su acción (Silva, 2001), propuesta que permitirá constatar de qué modo los sujetos docentes de esta investigación adquieren esta funcionalidad desde su condición profesional. Otro autor coetáneo, Henry Giroux (1990), defendió un enfoque liberador del currículum y una concepción de la escuela en la que esta permitiera el ejercicio de la 
democracia y de las habilidades inherentes a ella: la discusión, el razonamiento, el debate y la confrontación de ideas, procedimientos propios de la Historia, como se ha comentado anteriormente.

Esta tercera dimensión sobre los usos y finalidades de la Historia ligada a la educación para la ciudadanía crítica ha sido compartida y desarrollada por autores de diferentes espacios geográficos: el español, con Francisco García y Nicolás de Alba (2009); el inglés, con Hugh Starkey (2012); el francés, con François Audigier (1999) ○ Tutiaux Guillon (2003); ○ el estadounidense con David Schugurensky (2012), por citar ejemplos representativos. En todas estas aportaciones encontramos una nota característica: la apuesta por la educación cívica, ciudadana y política, conceptos que entrañan importantes diferencias. Entendiendo de un modo estricto la educación cívica como la formación en el comportamiento respetuoso de las normas de convivencia pública -quizás de manera acrítica o pasiva-, cabría dar un paso más hacia la educación de la ciudadanía y apostar claramente por lo que Goldberg y Savenije (2018), Ramos (2016), Levstik y Barton (2008) y McCully y Barton (2007) han señalado, la participación en controversias reflexivas, la conformación de posiciones independientes en el alumnado, el análisis de diferentes puntos de vista a partir de distintas fuentes, así como la comprensión de problemas actuales relacionados con la polis (Muñoz, 2017). Estas habilidades políticas democráticas permiten cuestionar e impugnar el currículum establecido y desnaturalizar lo que se da por real (Romero, 2018), así como situar al docente en una posición beligerante hacia posturas antidemocráticas de diversa índole (Trilla, 1992).

Para ello, es fundamental que esta educación histórica de carácter crítico una la educación en las habilidades democráticas y las destrezas del saber histórico a la de la construcción de identidades plurales, múltiples e inclusivas, pues de lo contrario se continuaría perpetuando la asunción de identidades asumidas de manera naturalizada. Como bien señaló Silva (2001), haciendo mención a las aportaciones de las teorías críticas y poscríticas, el currículum como espacio de poder transmite ideología y reproduce estructuras sociales. En este sentido, resulta una tarea urgente deconstruir los rasgos eurocéntricos, androcéntricos y heteronormativos del currículo para avanzar hacia una mayor incorporación de los enfoques del posmodernismo, el poscolonialismo, el feminismo y la pedagogía crítica (Segall, Trofanenko y Schmitt, 2018). La toma de perspectiva desde un punto de vista plural facilitará que el alumnado aplique los aprendizajes a nuevos contextos de una manera autónoma (Lesh, 2011) e, incluso, permitirá enfocar la educación hacia la orientación ética del alumnado (Rüsen, 2005, 2015).

Es evidente que apostar por visibilizar la multivocalidad de la historia, así como generar espacios educativos para valorar la diversidad de perspectivas sobre los acontecimientos históricos, implica una opción docente y decisiones en cuanto a qué historia enseñar y cómo hacerlo. La multiperspectividad en la construcción del relato histórico supone incluir diferentes narrativas que incidan en su carácter intersubjetivo (Wansink, Akkermann, Zuiker y Wubbels, 2018). Ello implica una serie de reflexiones por parte de los docentes desde el punto de vista historiográfico. En este sentido, la renovación en la historiografía planteada por la Escuela de Annales pero, sobre todo, en los años 60 del siglo XX, supuso abordar temas que habían quedado marginados de la academia: sujetos subalternos que no habían estado presentes, como las mujeres o los obreros. Comenzó a tomar forma la historia desde abajo, poniendo el foco de análisis en los sujetos que permanecían aún fuera de los relatos históricos de los grandes personajes y acontecimientos. Algunas de las corrientes historiográficas más fecundas fueron la historia social y sociocultural, la 
historia del movimiento obrero o la historia de género. Resultará de gran interés observar en qué posición se sitúan las docentes entrevistadas sobre este aspecto en particular, dado que algunas investigaciones (Montaña, 2015; Parra, 2010) han incidido en la falta de formación historiográfica de los futuros maestros y profesores, lo cual puede llevar a concebir la historia, no como una construcción sociocultural multivocal, sino como un relato cerrado, incapaz de formar políticamente al alumnado, algo constatado también por investigaciones sobre los recuerdos del alumnado de su etapa escolar (Gómez, Rodríguez y Mirete, 2018; Parra, 2019). Aun así, y aunque se escapa del alcance planteado en nuestra investigación y enlaza con los debates de la transposición didáctica (Chevallard, 1997; Mattozzi, 1999), habrá que considerar cómo se incorporan los avances historiográficos en las aulas (Prats, 1997), valorando al mismo tiempo cómo la escuela es capaz de construir un conocimiento que vaya más allá de la mera transformación desde un saber sabio o científico. En este proceso de descontextualización y recontextualización el saber escolar adquiere una especificidad evidente, rompiendo ese carácter de mímesis con el saber académico que, en ocasiones, ha postergado a la escuela a un lugar secundario (Cuesta, Mainer y Mateos, 2008).

\subsection{El papel del profesorado de historia en la formación política del alumnado}

Enlazando con lo anterior, las decisiones docentes tienen un protagonismo clave para el desarrollo de una educación crítica. Estas decisiones sobre la construcción del conocimiento histórico en el aula supondrán desarrollar unas actitudes en el alumnado en relación al pasado, así como unas destrezas históricas que influirán en sus habilidades democráticas, aun teniendo en cuenta la limitación de la escuela como formadora de una cultura política. La influencia del profesorado sobre el alumnado en este sentido ha sido analizada por autores como Fuertes (2016), que valoró el grado de formación política y de cuestionamiento de la dictadura que ejercieron los profesores del Tardofranquismo a partir de la enseñanza de la Historia. Este autor valoró que, si bien este modelo docente fue minoritario por causas evidentes, tuvo una repercusión notable en el alumnado, lo cual también constata Asensi (2017) en un contexto temporal más reciente al investigar acerca de cómo el alumnado educado desde un punto de vista problematizador recuerda mejor y de manera más compleja los contenidos históricos aprendidos. Asensi (2017) concluye que el hecho de que el alumnado asuma posturas poco históricas acerca del pasado concretamente ella analiza las percepciones sobre el Estado del Bienestar que tienen antiguos alumnos de Bachillerato-, se debe a un tipo de enseñanza de la historia poco crítica y de carácter memorístico. En esta misma dirección, convendrá ahondar en la capacidad de agencia del alumnado educado históricamente desde un punto de vista crítico, valorando su capacidad para deconstruir representaciones sociales e identidades naturalizadas. Algunos estudios empíricos recientes (Miguel-Revilla y Sánchez-Agustí, 2018) han permitido concluir, tras una aplicación en una investigación de aula basada en las categorías de conciencia histórica de Rüsen, que el alumnado capaz de construir visiones históricas complejas y críticas es minoritario. No obstante, estos autores también plantean que es posible realizar, desde la asunción de un modelo docente crítico, propuestas didácticas en que el alumnado tenga un protagonismo esencial en el debate entre pasado y presente a partir de una cuestión controversial.

Por tanto, teniendo en cuenta las investigaciones teóricas y empíricas realizadas, abordaremos el análisis de los usos y finalidades de la Historia escolar y la vinculación con la formación política desde la enseñanza y el aprendizaje de esta materia. Para ello, atenderemos a la diferenciación de tres modelos docentes: un modelo técnico o tradicional, basado en la reproducción de 
identidades naturalizadas, como las políticas; un modelo práctico, cuya base pedagógica es el constructivismo y pone el acento en las habilidades de pensamiento histórico; y un modelo crítico que, como se ha comentado, busca la emancipación de la persona mediante la comprensión y el cuestionamiento del presente y su participación en la polis.

El modelo crítico no parece estar mayoritariamente implantado en las aulas españolas y ello ha sido constatado por investigaciones diversas para momentos diferentes como la de Parra (2013) centrada en el alumnado de los últimos años del antiguo BUP, en que analiza la carencia de usos públicos críticos de la historia enseñada. El autor también advierte acerca de las resistencias actuales por la presencia de posturas neopositivistas que apuestan por una enseñanza pretendidamente neutral. Este último aspecto también fue investigado por Martínez (2013) en su tesis doctoral acerca de la enseñanza de la Transición en docentes. Este concluyó que predominan visiones poco críticas entre el profesorado y representaciones de la ciudadanía muy restrictivas, suponiendo este hecho una apuesta muy poco decidida por una enseñanza problematizada que aborde la controversia y la formación política. Se tratará en esta investigación de detectar de qué modo se configuran los modelos docentes en las profesoras investigadas y si sus decisiones pedagógicas contribuyen a la adquisición de habilidades democráticas en el alumnado.

\section{Metodología de la investigación}

La pretensión de esta investigación es analizar los usos y finalidades de la Historia escolar en el contexto de un aula en relación a la formación política que recibe el alumnado. Para ello, se ha propuesto utilizar una metodología de investigación de tipo mixto, que permite comparar perspectivas que provienen de datos cualitativos y cuantitativos (Angulo y Redon, 2017; Holloway, 1997; Van Maanen, 1983). Así, a partir de estos objetivos de la investigación diseñamos un estudio de campo descriptivo, naturalístico y contextual. Es un estudio no experimental, dado que no se busca intervenir en las variables estudiadas, sino analizar los discursos y los materiales que se han considerado como instrumentos de investigación (Albert, 2006).

La dimensión cuantitativa proviene de la recogida de datos del alumnado de Educación Secundaria, analizando así un caso con bastantes variables y constituyendo una investigación posterior al hecho, ex post-facto. En primer lugar, se ha producido el hecho (las clases de los grupos de la ESO y la impartición de un curso académico por los docentes) y después se han analizado las percepciones del alumnado.

La dimensión cualitativa, que tiene una fuerte presencia en la investigación, se aborda mediante el análisis de los discursos y representaciones del alumnado, así como de sus docentes. Esta dimensión permite poner la atención en lo particular, establecer comparaciones sobre el caso analizado y entender la realidad de manera holística.

El trabajo de campo se caracteriza por disponer de una muestra compuesta por 2 docentes y 68 alumnos, de tipo casual o por facilidad de acceso (Bisquerra, 1989), escogida por criterios de proximidad al caso de estudio. El alumnado pertenece a diferentes grupos de $1 .^{\circ}$ y $4 .^{\circ}$ de ESO, cuyos docentes son los analizados en la investigación pertenecen a un centro de Educación Secundaria de la provincia de Valencia del curso escolar 2017-2018, centro con una población de 975 alumnos y 85 profesores. La diversidad dentro del alumnado permite observar diferentes 
tendencias y comportamientos en grupos del mismo nivel, así como establecer comparaciones entre diferentes cursos. Las características de las docentes son las siguientes:

- A. R.: docente, de sexo femenino, de 26 años, graduada en Historia, Máster de profesor de Educación Secundaria Obligatoria, impartiendo clase desde septiembre de 2017 como funcionaria interina.

- M. E.: docente, de sexo femenino, de 28 años, licenciada en Historia, Máster de profesor de Educación Secundaria Obligatoria, impartiendo clase desde septiembre de 2017 como funcionaria interina.

Respecto al alumnado, estos se distribuyen de la siguiente forma:

- 1. ESO C: 15 alumnos, profesora M. E. En este grupo hay generalmente un buen comportamiento y diferentes ritmos de trabajo: mientras un conjunto de la clase tiene asumidas unas pautas continuas de trabajo y un buen acompañamiento familiar, hay otro conjunto de alumnos con dificultades que trabajaba con material adaptado. Es una clase con alumnado de origen local o de pueblos cercanos, con una minoría de alumnos de etnia gitana.

- 1. ESO G: 12 alumnos, profesora A. R. En este grupo hay un clima de trabajo más difícil, con un comportamiento, en ocasiones, poco adecuado para la dinámica del aula. El nivel académico es bajo y los objetivos del currículum se adaptan a un nivel más básicos. Hay una mayoría inmigrante en el aula de alumnos con orígenes diversos (Sudamérica, Europa del este, Marruecos).

- 4..$^{\circ}$ ESO C: 20 alumnos, profesora A. R. En este grupo hay un buen comportamiento generalizado, a pesar del nerviosismo que hay en ellos en ocasiones. El nivel académico es ordinario y no presenta grandes disparidades. Es una clase con una gran mayoría del alumnado de origen local.

- 4. ${ }^{\circ}$ ESO A: 21 alumnos, profesor N. B, autor de la presente investigación. En este grupo hay un comportamiento óptimo con interés hacia el estudio y el trabajo. El nivel académico es muy bueno en general y el alumnado es, en su gran mayoría, de la localidad del centro educativo. La inclusión de este grupo, con un docente diferente, se debe a la disponibilidad existente en el centro para obtener dos grupos del mismo nivel, así como para facilitar la diversificación de los puntos de vista en las respuestas del alumnado.

Los instrumentos de investigación han sido sometidos a una validación por expertos en el campo de la Didáctica de las Ciencias Sociales, siendo estos, la investigación por encuesta con el instrumento de recogida de datos del cuestionario, desde la dimensión cuantitativa; y la entrevista semiestructurada y las narrativas desde la dimensión cualitativa. Todo el trabajo de campo se ha realizado al finalizar el curso escolar 2017-2018 durante el mes de junio en un corto espacio de tiempo, llevándose a cabo en primer lugar el cuestionario y la narrativa al alumnado y, posteriormente, las entrevistas a las docentes. Ello obedece al objetivo de indagar en las percepciones de docentes y discentes sobre lo ocurrido durante un año académico, sin intervenir directamente en el desarrollo de las clases. 
Respecto al cuestionario, este se ha utilizado con el alumnado con el fin de servir como instrumento de recopilación de datos y se ha dividido en dos partes claramente diferenciadas. En primer lugar, se han diseñado cuatro preguntas cerradas, con diferentes ítems, que tienen el objetivo de establecer regularidades en cuanto a las respuestas mediante una escala Likert (Bisquerra, 1989). En segundo lugar, se han incluido cuatro preguntas abiertas que permiten obtener información directa del alumnado a partir de sus propias palabras. El objetivo es indagar en la metodología de las clases de la materia de Historia, detectar diferencias entre los grupos en cuanto a las estrategias metodológicas, conocer la visión del alumnado acerca del rol del profesor y profundizar en sus representaciones sobre la materia y su contribución a la formación política.

En cuanto a la entrevista semiestructurada, esta ha sido escogida por ser un instrumento de investigación cualitativa óptimo para analizar las ideas, los diferentes puntos de vista y representaciones de las dos docentes investigadas (Ruiz, 2009). Se han diseñado cinco grandes preguntas, guardando un orden progresivo y generando un clima fluido de conversación controlada y profesional. La naturaleza de la entrevista semiestructurada permite realizar pequeñas modificaciones en la ejecución de la entrevista gracias a la flexibilidad que permite este tipo de instrumento, e incluso solicitar a las entrevistadas aclaraciones para profundizar en algún punto. El objetivo de las entrevistas ha sido el de conocer el posicionamiento docente ante temas conflictivos en la materia de Historia, conocer la propia visión acerca de la metodología empleada en el aula, así como indagar en la opinión del profesorado en cuanto a la formación política derivada de la enseñanza del tiempo histórico.

En referencia a la narrativa, instrumento de investigación cualitativo, se solicitaba mediante una pregunta abierta que el alumnado escribiese una carta a un compañero de un curso anterior explicándole cómo se había abordado en el aula un tema determinado del nivel cursado. Este instrumento se ha utilizado en otras investigaciones de referencia para analizar otras dimensiones de la enseñanza de la materia (Gómez y Sáiz, 2017). En el enunciado de la narrativa se escogieron temas controversiales y abiertos, con el fin de valorar de qué modo se enseñaron en el aula e indagando en la cuestión de si se abordaron o no desde una dimensión crítica y política. En el caso de $1 .^{\circ}$ ESO se pudo optar por redactarla acerca de cómo se abordó el concepto de democracia en la Atenas clásica o la expansión de Roma; mientras que en el caso de $4 .^{\circ}$ ESO las opciones fueron el estudio de los totalitarismos, o del pasado traumático de España: la Guerra Civil y el Franquismo. En los enunciados de las narrativas se introdujeron las siguientes subpreguntas con el fin de guiar al alumnado y permitir un mayor desarrollo: "iSe emitieron opiniones en clase? ¿ ¿Consideras que el profesor tomó partido o expresó su opinión? ¿̇Hubo alguna comparación con la actualidad o entre épocas históricas?"

En cuanto a los procedimientos de análisis de los instrumentos expuestos, se ha optado por las técnicas más adecuadas, de acuerdo a la naturaleza cuantitativa y cualitativa de estos. En el caso de los cuestionarios, se ha establecido una diferencia en el procedimiento para las preguntas cerradas y las preguntas abiertas. En el caso de las preguntas cerradas, la técnica de análisis fue el empleo de hojas de cálculo y la elaboración de gráficos para comparar grupos y preguntas diferentes que remiten al mismo objeto de estudio, con el objetivo de corroborar las tendencias observadas.

En cuanto a las preguntas abiertas del cuestionario y las narrativas, se ha optado por analizarlas por medio del método cualitativo de análisis de contenido (Ruiz, 2009), del mismo modo que las 
entrevistas al profesorado. Al tratarse de datos expresados de manera narrativa, y desde una dimensión cualitativa, se ha tratado de captar los significados de manera profunda. Para ello, se ha seguido el proceso de codificación propuesto por Strauss y Corbin (2002), inmerso en un proceso de selección, categorización, comparación e interpretación (Bisquerra, 1989). Con la finalidad de reducir la información y poder trabajarla, se han extraído una serie de unidades de significado que han permitido segmentar los textos. Las unidades de significado son unidades mínimas que tienen un sentido que se puede individualizar atendiendo al marco de los objetivos de la investigación. Estas unidades de significado fueron agrupadas provisionalmente en códigos, proceso útil para definir la manera de trabajar con los datos que se están analizando y para recuperar posteriormente su significado (Gibbs, 2012). Los códigos permitieron agrupar unidades de significado que ejemplificaban una misma idea para, posteriormente, incluirlos en categorías. La codificación es una tarea que requiere trabajar sistemáticamente con los datos, por lo que se ha optado por la combinación de una lógica inductiva y una deductiva (Ruiz, 2009). Por ello, se ha establecido en primer lugar una organización inicial de los datos para, posteriormente, ajustar la codificación a nivel más teórico y lograr una mayor coherencia que permita indagar en los objetivos de la investigación.

Las categorías han permitido agrupar diferentes códigos bajo criterios temáticos para, de este modo, facilitar el posterior análisis. El instrumento utilizado para organizar y trabajar con los datos ha sido el de las matrices o cuadros de doble entrada, que ha permitido comprender una perspectiva global de los datos y facilitar la comparación. Dado que el proceso de categorización ha supuesto una agrupación en amplios marcos de información, ha sido necesario establecer subcategorías que agruparan códigos de semejante temáticas para poder trabajar de manera sistemática con los datos.

Con el objetivo de facilitar el análisis y la posterior comparación, así como por la naturaleza diversa de los datos, se ha optado por emplear diferentes agrupaciones códigos para los instrumentos de investigación del profesorado (entrevista semiestructurada) y para los del alumnado (preguntas abiertas del cuestionario y narrativa). Aun así, las diferencias no han sido muy significativas y se ha mantenido la estructuración básica de las grandes categorías.

En el caso de la entrevista semiestructurada, las categorías explicativas han sido las siguientes: "Usos y finalidades de la Historia", que agrupa códigos referidos a la utilidad otorgada por los docentes al pensamiento histórico, las finalidades de la historia escolar y la formación política en esta materia; "Contenidos y enfoques científicos", en la que se han sistematizado las referencias a enfoques científicos positivistas y plurales en la enseñanza de la historia, así como los contenidos trabajados en el aula que tienen relación con la formación política; "Metodología didáctica", categoría en la cual se ha considerado necesario incluir subcategorías para sistematizar la información acerca de las estrategias de enseñanza, el papel del docente, la dinámica de aula, las dificultades en la enseñanza de la historia y la evaluación; y "Concepciones sobre la formación política", en que se han incluido los códigos referidos a las concepciones acerca del sistema educativo y su papel en la formación política del alumnado.

Respecto a los instrumentos que indagan en las percepciones del alumnado, se han sistematizado las mismas categorías, generándose leves modificaciones en cuanto a la codificación. En la categoría de "Usos y finalidades de la historia" se han incluido no solo aspectos sobre las finalidades de la materia, sino también las referencias a la actualidad en el aula de Historia, así 
como cuestiones epistemológicas de la disciplina. En la categoría "Contenidos y enfoques científicos" se ha establecido una diferencia entre contenidos trabajados en los diferentes niveles educativos y entre enfoques positivistas y plurales del saber histórico. En la categoría de "Metodología didáctica" se han abordado aspectos como el papel del docente, las estrategias de enseñanza, los materiales y la evaluación. Por último, en la categoría de "Concepciones sobre la formación política" se ha convenido incluir todo lo relacionado con la adopción de posturas referidas a la imparcialidad, la neutralidad y la presencia de temas políticos en el sistema educativo.

El proceso de categorización ha permitido dar un paso hacia la interpretación del texto y facilitar la comparación entre la visión del alumnado y del profesorado, teniendo presente la pregunta de investigación, que ha servido para hacer las revisiones y modificaciones pertinentes en todo este proceso de análisis de contenido.

El análisis de los datos, tanto los provenientes del alumnado como especialmente del profesorado, se ha abordado empleando una serie de modelos didácticos, caracterizados de manera general, inspirados en las aportaciones de Rozada (1997), Pozo, Asensio y Carretero (1989) y Silva (2001) desde el campo de la Pedagogía y de la Didáctica de la Historia. Estos modelos, sistematizados bajo un modelo de tipos ideales, son tres: la Historia como reproductora de identidades, la Historia como método y la Historia en su relación con el presente, desde la perspectiva informadora o transformadora. Estos modelos se suelen presentar de manera híbrida y se pueden sistematizar en tres visiones o paradigmas de la enseñanza de la historia: la tradicional, la práctica y la crítica, como se ha desarrollado anteriormente. Los rasgos de estos tres modelos se analizarán en las docentes entrevistadas para valorar de qué modo y en qué grado participan de ellos, así como en las declaraciones del alumnado, con el objetivo de comparar los datos. Se asume que este estudio supone tan solo un acercamiento a un campo de investigación que requiere de mayor desarrollo y que se antoja fundamental para comprender lo que se desarrolla en las aulas, ese espacio privilegiado para entender el papel de la escuela en la formación de la ciudadanía.

\section{Resultados y discusión}

\section{1. "Con la finalidad de ser un ciudadano activo...": percepciones del profesorado acerca de la finalidad de la Historia}

Las percepciones e ideas del profesorado acerca de su disciplina condicionan la práctica educativa que implementan, por lo que conviene realizar un análisis de estas concepciones en las dos docentes entrevistadas. Para ello, se seleccionarán unidades de significado relevantes de acuerdo con las categorías establecidas, que nos servirán para analizar las percepciones de las docentes y llegar a una serie de conclusiones sobre sus perfiles profesionales. Queda patente en primer lugar que, en ambas profesoras, existe una convicción profunda de que la historia debe formar cívica y políticamente al alumnado -de acuerdo con las propuestas teóricas de autores como García y de Alba (2009) o Starkey (2012)-, considerándose esta como una función absolutamente relevante. Esta convicción se puede observar en las entrevistas en reiteradas ocasiones: "hay una falta de sentido cívico o sobre todo de sentido político dentro de nuestras 
aulas"' (M. E.); "si no se hace se tiene una generación que está dormida, es pasiva" (M. E.); o "... para poder participar de forma activa en la política, debes formar al alumnado para que entiendan lo que está pasando y sepan cuál es la variedad de posibilidades políticas o la situación política del país, o a nivel internacional, que están viviendo". Para A. R. también resulta clave enfocar la historia desde el objetivo de que los alumnos "tomen conciencia de la situación actual y de cuál puede ser su papel delante de esa situación política". Consideran ambas que esta materia -con mayor facilidad que otras- permite generar un espacio aprovechable para tratar temas que se vinculan fácilmente con lo político y los problemas actuales, lo cual supone ligar la educación histórica con la construcción de la ciudadanía (Haste y Bermúdez, 2017). Además, A. R. piensa que la gran mayoría de los docentes utilizan este enfoque en sus clases algo que, si bien requiere una investigación más extensa, no parece constatarse a partir de lo analizado por autores como Martínez (2013), que señala que predomina una concepción minimalista de la ciudadanía en los docentes, centrada en aspectos como los derechos y deberes, pero no en la promoción de la participación social; o por Parra (2013), que indica que este enfoque está sometido a resistencias por la tendencia a evitar el conflicto en las clases de Historia y optar por una disciplina concebido de modo más tradicional o neopositivista.

No obstante, existen algunas diferencias entre ambas docentes. El discurso generalista de que la educación y, por ende, la Historia como disciplina escolar debe ayudar a fomentar un carácter participativo y activo en la sociedad -ideas presentes en la tradición de la pedagogía crítica: Dewey (1995) o Silva (2001)-, se concreta con diferencias respecto al modo de enfocar la materia. Mientras A. R. afirma que la formación política desde la historia debe suponer un conocimiento amplio para el alumnado de las diferentes opciones políticas que existen en el mundo, M. E. va más allá en este sentido y afirma esta debe formar políticamente, incluso censurando opiniones "radicales" o "marginaciones sexuales, morales y racistas" que se puedan dar en el alumnado. Vemos, en este caso, una interpretación de las ideas del docente como intelectual transformador (Giroux, 1990; Silva, 2001), en la que no solo se trata de facilitar el aprendizaje de determinadas culturas políticas, sino que se deben cuestionar ideas pertenecientes al ámbito personal del alumnado en aras de su completa formación como ciudadano. Posteriormente en la entrevista, la docente desarrolla esta idea y verbaliza su convicción de que existe un "espacio compartido" en la escuela, es decir, unos valores generales y transversales que deben ser impulsados. Para esta profesora, cualquier ideología no está permitida dentro del sistema educativo, sino que hay un conjunto de valores aceptados en los que la escuela debe implicarse, defendiéndolos más allá de las opiniones que puedan tener los alumnos o sus familias, haciendo una clara referencia a los posibles puntos de vista que aparecen en las aulas que incurren en algún tipo de discriminación. La mayor implicación de M. E. defendiendo un discurso en el que la historia debe tomar un papel transformador contrasta con lo sugerido por su compañera A. R., como veíamos en las citas anteriores. M. E. considera que las acciones desde las aulas para impulsar un sentido cívico y político en el alumnado son claramente insuficientes y, si bien es esta una percepción subjetiva y parcial, considerarla como punto de partida para examinar su práctica docente en esta investigación resulta de gran interés, pues se ubica en la defensa de una concepción de la ciudadanía que va más allá del mero conocimiento de culturas

1 Las citas originales de las entrevistas y de las narrativas se encuentran en catalán. Se han traducido al castellano para facilitar su comprensión. 
políticas, derechos y deberes, sino que incluye también la dimensión ética y participativa (Ramos, 2016; Levstik y Barton, 2008; McCully y Barton, 2007).

Al hilo de lo anterior, las ideas sobre los usos de la materia no constituyen ideales puros en la conceptualización de modelos docentes, sino que más bien se configuran de manera compleja con la intersección de paradigmas diferentes, aspecto que se analizará mediante la comparación con las fuentes procedentes del aula. Desde el plano de las declaraciones de intenciones de las docentes, no se puede advertir un posicionamiento a favor de un modelo tradicional que busque la reproducción de identidades acríticas, siguiendo los enfoques mencionados anteriormente de Rozada (1997), Pozo et al. (1989) y Silva (2001). De hecho, A. R. afirma que en el aula debe plantearse la presencia de la ideología en la conformación del currículo con el objetivo de que "los alumnos se cuestionen el material que se está dando en clase". Advertimos aquí una reflexión por parte de la docente acerca de la deconstrucción del currículo y su desnaturalización (Segall, Trofanenko y Schmitt, 2018; Silva, 2001), si bien no se observa que se desarrolle el necesario tratamiento de las identidades nacionales como constructos históricos, o la presencia explícita de perspectivas historiográficas que tengan en cuenta los nuevos paradigmas anteriormente mencionados (Parra, 2010). De hecho, en el caso de A. R. sí aparecen referencias explícitas a la necesidad de enseñar contenidos de ideologías políticas, desde el punto de vista de la historia intelectual clásica, dando cuenta de una diversidad en el acercamiento que los docentes hacen a la educación ciudadana, como se ha podido observar en investigaciones de caso (Estellés, 2015). No obstante, la docente no da el paso cualitativo de complejizar esta enseñanza valorando la receptividad y la capacidad de agencia de los individuos, o de insertarla en los debates y conflictos actuales, por lo que se puede afirmar que su postura es en este punto ambigua y el análisis requiere ser completado mediante la acción en el aula.

El modelo práctico (Rozada, 1997), orientado al desarrollo de habilidades del historiador, también está presente en las docentes. Por ejemplo, se fomentan destrezas como el comentario de texto por parte de A. R., exclusivamente centrado en las fuentes, mediante un guion estereotipado que no facilita, a priori, ir más allá del documento, deviniendo en una aplicación de las competencias clave de modo muy pobre (Sáiz, 2013a). En el caso de M. E., se afirma que "apostaría por un método en el que se desarrollaran debates o cuestiones que hicieran pensar al alumnado", lo cual ofrece un salto cualitativo y se puede ubicar en un modelo práctico o crítico, dependiendo del desarrollo de este debate.

Reconociendo la complejidad de los modelos y la necesaria comparación con la práctica de aula, las ideas verbalizadas por M. E. y A. R. las sitúan, en principio, en un modelo crítico de enseñanzaaprendizaje de la Historia que habría de redundar en el aprendizaje de las habilidades democráticas en el marco de una ciudadanía participativa (Heimberg, 2009). Ambas afirman que conviene que el alumnado tome conciencia de la situación del mundo actual y actúe de manera activa como ciudadano. Todo ello es considerado necesario por las docentes para evitar la ignorancia y para construir una ciudadanía crítica, dado que se considera que la ignorancia en sentido político afectará al alumnado en su vida (García y de Alba, 2009; Starkey, 2012). De hecho, A. R. afirma de modo tajante que, de no llevar a cabo esta educación política en el aula el alumnado podría acabar viviendo "en un mundo paralelo en el que no saben nada de política y eso en el día de mañana les va a afectar". Para llevar a cabo este enfoque, defienden incluso un enfoque problematizador de la Historia que establezca comparaciones entre épocas. En este sentido, A. R. señala que la Historia "debería centrarse más en extrapolar (...) estos 
debates de historia antigua, de historia medieval a lo que pasa hoy en día". El enfoque problematizador y el recurso a los problemas sociales relevantes estableciendo comparaciones entre pasado y presente son, según algunos autores (López y Santidrián, 2011; Muñoz, 2017), la clave para un enfoque crítico de la Historia, que huya de los usos y finalidades tradicionales y que permita el cuestionamiento del orden sociopolítico actual. No obstante, convendrá en los siguientes puntos poner en relación estas ideas iniciales de las docentes con la práctica real de aula para examinar con mayor profundidad qué estrategias se implementan.

\subsection{Entre dificultades y oportunidades: "las grietas del currículum"}

Tras esbozar el panorama sobre la utilidad y la función de la Historia en el caso concreto de dos docentes, conviene, de manera previa al análisis de la dinámica de aula, cuestionarse sobre dos aspectos: ¿̇cómo considera el profesorado que puede ser la práctica docente de la Historia según la legislación vigente en educación? Y ¿cuáles son las dificultades que observa para implementar un modelo de enseñanza crítico de la Historia que redunde en la formación política del alumnado?

Una de las preguntas que se han planteado a las entrevistadas para examinar sus percepciones acerca de la legislación vigente es la de si el Preámbulo de la Ley Orgánica para la Mejora de la Calidad Educativa en España (2013) se cumple en la realidad de nuestro sistema educativo. Ambas responden de forma clara que no. Recordemos que en este Preámbulo se indica que la escuela debe fomentar la autonomía, el sentido crítico y el pensamiento propio del alumnado, así como conseguir un espíritu emprendedor. M. E., por ejemplo, señala que "en parte no se hace nada" para desarrollar el sentido cívico y político. Por tanto, resulta interesante observar el cambio de perspectiva que se produce respecto a la historia enseñada cuando se les cuestiona sobre la normativa educativa -que marca unos objetivos generales ambiciosos-, en contraste con las opiniones más optimistas que manifestaban al comentar los modelos docentes más habituales que consideran que sí educan de un modo más crítico. Recordemos que A. R. señalaba que "los profesores que conozco (...) sí forman políticamente". Estas diferencias podrían derivarse de poner en relación la práctica real -tanto propia como la conocida de los compañeros- con los objetivos de máximos que establece la legislación.

Tratando de justificar lo anterior, las docentes entrevistadas manifiestan una serie de dificultades generalizadas para llevar a cabo un enfoque problematizador que sirva para la construcción de una ciudadanía democrática desde el aula. Una de estas dificultades es la propia legislación, que consideran inadecuada para el tratamiento de problemas históricos. Las leyes educativas han presentado tradicionalmente una sobrecarga de contenidos que difícilmente pueden llevarse a cabo completamente en el aula. La LOMCE estableció una excesiva carga de estándares de aprendizaje, gran parte de ellos muy complejos y con gran carga enciclopédica (Trepat, 2015), lo cual impide adquirir "conocimientos históricos rigurosos" (López, 2014, p. 282), dado que por limitaciones evidentes de tiempo no es posible profundizar. Tanto Trepat (2015) como López (2014) realizaron sus respectivos análisis acerca de la gran cantidad de criterios de evaluación y de estándares existentes en cada uno de los cursos, mostrando el claro alejamiento de esta ley respecto al sentido común de cualquier docente, conocedor de la imposibilidad de llevar a cabo el planteamiento establecido. Estas limitaciones son advertidas por parte de M. E. al referirse a $2 .^{\circ}$ ESO como un nivel con un currículum construido en base al memorismo (Cuesta, 1997), con una gran cantidad de contenidos de historia medieval considerados por ella como "complejos para niños de 13 ○ 14 años". En el mismo sentido, la profesora A. R. se refiere a las dificultades 
encontradas en $4 .^{\circ} \mathrm{ESO}$ en el momento de abordar el siglo XIX español desde un punto de vista crítico y que genere debates sobre la actualidad.

Si bien estas dificultades están presentes y son inherentes a la construcción del conocimiento histórico, las profesoras consideran que la acción docente, la investigación y la implicación personal y profesional pueden ser claves para buscar "grietas dentro del currículum para trabajar de manera crítica", en palabras de la profesora M. E. En este sentido, pensamos que hay un margen suficiente por la vaguedad y generalidad de los criterios de evaluación para optar por metodologías activas, enfoques plurales y problemáticos en la enseñanza de la historia que contribuyan a la educación política del alumnado. La plasticidad del currículum permite organizar actividades donde se emplee una metodología más activa y crítica con el conocimiento histórico (Sáiz, 2013b). Ello lo permite la inclusión de este enfoque -si bien de manera generalista y poco arriesgada- en algunos criterios establecidos por la normativa, y la presencia de conceptos comunes en historia (cambio, continuidad, pensamiento alternativo...) (Seixas y Morton, 2013), tan importantes como los contenidos factuales (Lee y Ashby, 2000). Además de ello, la paralización de algunas de las medidas más controvertidas de la LOMCE como la realización de pruebas evaluables externas, ha permitido aligerar la carga del currículum y recuperar un mayor grado de libertad en la impartición de los contenidos. Consideramos que el papel del docente en la adaptación de conocimientos científicos y su traslado al aula es clave, con la finalidad de dotar a estos de un enfoque problemático y formador dentro de una sociedad democrática. Profundizar en la tarea del docente acerca de la reconstrucción del saber escolar (Prats, 1997) es una tarea todavía pendiente según lo analizado en este caso, dado que se advierten carencias en cuanto a la interpretación y gestión del currículo.

Otro de los elementos que dificultan la tarea docente desde un paradigma crítico, según las entrevistadas, es la relación entre objetividad y subjetividad en Historia. Existe un temor evidente en las docentes hacia las críticas familiares, derivadas de la representación social hegemónica de la Historia como relato objetivo y cerrado, no abierto a interpretaciones diferentes que aborden de manera explícita las implicaciones políticas que tiene el estudio del pasado. La profesora A. R. comentó en la entrevista una situación vivida en el aula de $1 .^{\circ}$ ESO en que se generó una comparación sobre el papel de la monarquía entre pasado y presente, momento en que el alumnado opinó y estableció comparaciones con cierto grado de madurez, como se advierte en las narrativas. Este puede ser un ejemplo de cómo la escuela es capaz de descontextualizar y recontextualizar saberes académicos en contextos áulicos (Cuesta, Mainer y Mateos, 2008). No obstante, la actuación de A. R. como docente no pareció aprovechar la situación didáctica desarrollada, dado que señaló que los alumnos de 1. ESO "son muy pequeños y después hablan en casa, y tal vez tienes algún problema", lo cual limitó su iniciativa a la hora de plantear temas conflictivos en el aula y la situó en la posición de la "neutralidad excluyente", según López y Santidrián (201 1, p. 13). La docente eludió el debate en el aula y evitó cuestiones controversiales.

Respecto a M. E., esta señala también que las clases de historia deben desarrollarse "sin emitir nuestra opinión", sin embargo, señala posteriormente que la neutralidad adoptada por los docentes debe basarse puramente en el aspecto partidista, no así en la defensa de unos valores compartidos considerados propios del sistema democrático, tal y como se comentaba anteriormente. La conveniencia de adoptar una postura neutral $\circ$ beligerante por parte del docente no tiene una respuesta unilateral y sencilla, sino que depende del objeto de conocimiento 
y de la situación de aula (Trilla, 1992). Asumimos la idea que, si bien es posible ser neutral en ciertos temas, conviene mostrarse beligerante en algunos, al hilo de lo defendido también por $M$. E., que planteaba que existían unos valores compartidos irrenunciables dentro del sistema democrático. Para Trilla (1995, p. 104) estos valores compartidos son "los propios de la democracia 0 , aun de forma más restringida, lo que podríamos llamar las reglas de juego del sistema democrático (...) la tolerancia, el respeto al pluralismo, la participación responsable, la renuncia al ejercicio de la violencia...". No obstante, pensamos que aducir la necesidad de la neutralidad en la enseñanza de la historia no puede justificar la ausencia de tratamiento de cuestiones controversiales, como se ha observado en el caso de A. R., dado que ello implicaría claudicar de la función docente de formar el alumnado en las coordenadas de la ciudadanía democrática. Por ello, y teniendo en cuenta el contexto reciente en que el profesorado está siendo cuestionado en esta tarea proyectada hacia la ciudadanía, es conveniente seguir investigando en esta línea y fomentar una reflexión en los docentes acerca de su posicionamiento educativo, con el fin de lograr con una mayor comprensión de conceptos como "neutralidad" o "beligerancia" en su aplicación al aula. Observaremos posteriormente cómo esta posición ambigua de las docentes se traduce en una dinámica de aula ambivalente, con estrategias de tipo neutral que conviven con otras más comprometidas.

Por último, cabría sumar también al conjunto de dificultades que observan las docentes para un tratamiento problemático de la historia la falta de materiales idóneos, dado que en los libros de texto predominan los relatos cerrados, inmutables e incuestionables (Gómez, Cózar y Miralles, 2014; Viñao, 2003), no siempre actualizados historiográficamente ni aptos para el contraste de puntos de vista diferentes que faciliten el desarrollo de habilidades democráticas, como se ha podido analizar desde puntos de vista diversos (Bel, Colomer y Valls, 2019; Fuertes, 2018; Sáiz, 2011). Ambas docentes consideran que esta es una limitación importante, dado que la elaboración personal de materiales alternativos -que consideran la mejor opción-, resulta inviable en la totalidad del curso escolar por la sobrecarga de trabajo. La profesora A. R. señalaba que, en caso de utilizar el texto "raramente (se) va a plantear este tipo de debate, debes rehacer tú el material y debes proponer tú la actividad en clase si quieres que ese debate surja de manera no espontánea, trabajada". De todos modos, la explicación que dan las docentes acerca de los problemas que plantea el manual como material escolar hegemónico en el aula se basa casi exclusivamente en cuestiones metodológicas. No se plantean en modo alguno reflexiones acerca del texto seleccionado por la editorial, la construcción del conocimiento que se hace, la concreción del currículo o la preocupación por cuestiones políticas y económicas, tales como el oligopolio de las editoriales, algo constatado en otras investigaciones empíricas (Martínez, 2013). Pensamos que un mayor debate acerca de estos temas permitiría seleccionar el material escolar de acuerdo con un paradigma crítico que reconozca la necesidad de educar en la controversia desde el aula, como estrategia para la educación ciudadana (Levstik y Barton, 2008). Por último, en las entrevistas no ha habido ninguna referencia a materiales alternativos externos realizados por grupos de innovación didáctica, lo cual indica que no son utilizados en este contexto, a pesar de que podrían suponer mejoras evidentes respecto al tema que nos concierne. 


\section{3. ¿"La historia es única, es la que es"?: complejidad de las representaciones del alumnado sobre la Historia escolar}

Conocer las percepciones del alumnado acerca de los usos y finalidades de la Historia resulta de utilidad, más aún cuando es posible ponerlas en relación con las de sus docentes. En este punto trataremos de sistematizar las representaciones que, sobre la Historia, se tienen por parte del alumnado de $1 .^{\circ}$ y $4 .^{\circ}$ de ESO para, posteriormente, comparar ambas fuentes de investigación.

En primer lugar, y sin la pretensión de ser exhaustivos con la cuantificación de los datos, existe un conjunto del alumnado tomado como muestra que se encuadra en la consideración de la historia como un relato cerrado, sostenedor y constructor de identidades no cuestionadas, algo representado por alumnos como el $4 \mathrm{~A} .8^{2}$ que afirma que "la historia es única, es la que es y no puede ser contada diferente". En este sentido, sigue existiendo un número considerable de alumnos que se sitúan en el modelo de las historias generales (Valls y Colomer, 2018) al concebir la historia como un relato que es capaz de sistematizarse en un manual de manera cronológica, concebido como depositario de la verdad. Esta visión ha sido constatada en investigaciones empíricas como las de Montaña $(2014,2015)$ para el caso de Educación Primaria, en las que afirma que tres de cuatro alumnos persisten en la idea de confundir pasado con relato histórico y de considerar que es posible conocer absolutamente lo ocurrido en tiempos pretéritos. En el caso de Secundaria, investigaciones como las de Miguel-Revilla y Sánchez-Agustí (2018) confirman la preeminencia de enfoques tradicionales o positivistas acerca del conocimiento histórico, algo también señalado por autores que han realizado semejantes análisis a partir del análisis de los exámenes de acceso a la universidad (Fuster, 2016; Martínez, Conejo y López, $2011)$.

Se puede observar esta apreciación en el primer gráfico (Figura 1) adjunto, en el que hay una clara mayoría de alumnos de $1 .^{\circ}$ ESO que responden afirmativamente a la cuestión de si es necesario el manual para estudiar correctamente Historia, resultados que permiten afirmar que se valora el libro de texto como depositario de un conocimiento cerrado y objetivo del pasado histórico. En el caso de $4 .^{\circ}$ ESO observamos grandes diferencias que suponen aplicar matices importantes a esta tendencia, por lo que no se puede concluir que la mayoría del alumnado haya interiorizado absolutamente una concepción acrítica de la historia. En el segundo gráfico (Figura 2) se puede observar una distribución semejante de los resultados: una gran dispersión en las respuestas del alumnado de $1 .^{\circ} \mathrm{ESO}$, y una mayor contundencia en rechazar por parte del de $4 .^{\circ}$ ESO la consideración de la historia como el relato de los manuales escolares.

2 Se identifica así a cada alumno para localizar el curso y grupo. 


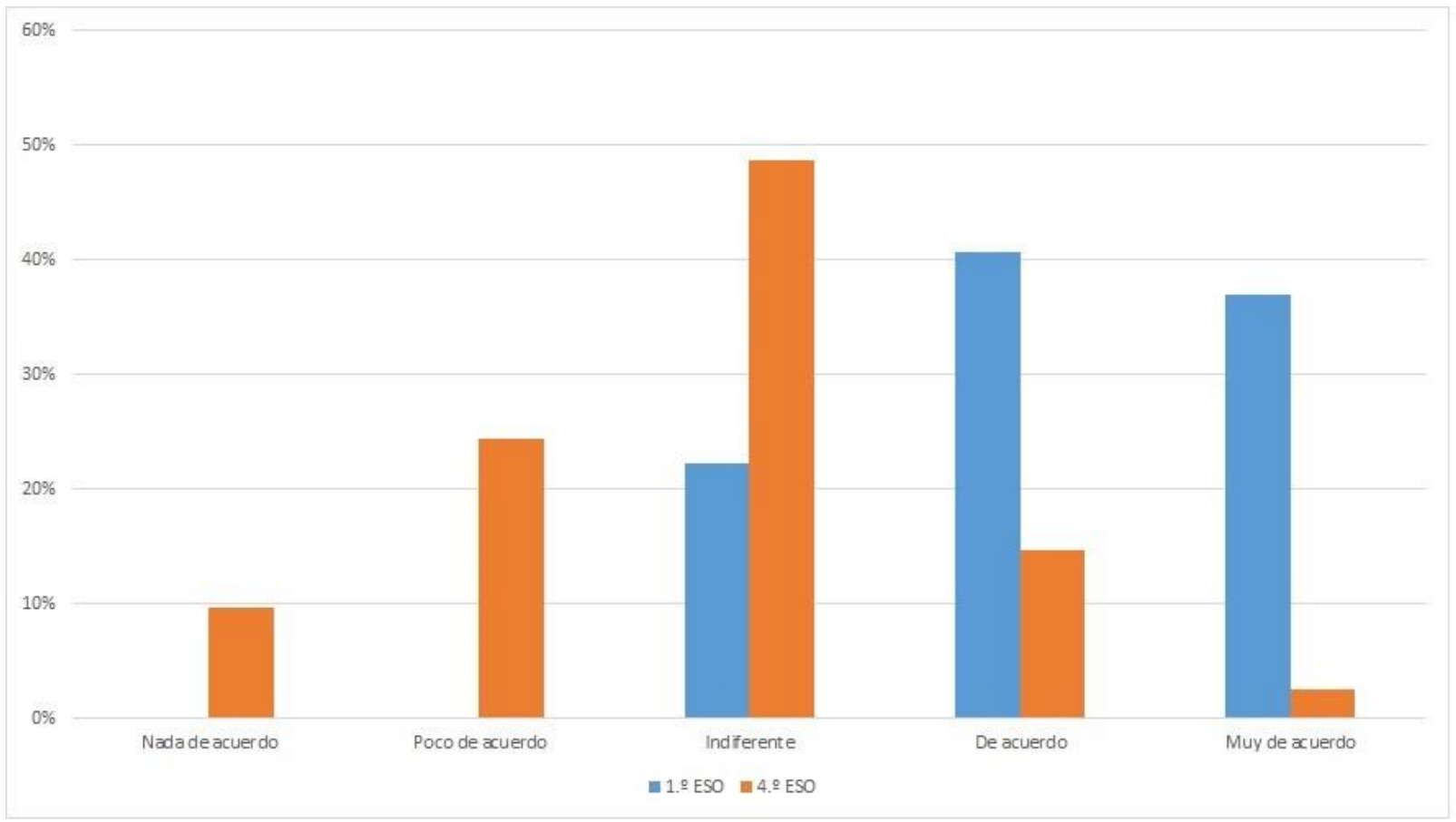

Figura 1. Percepciones sobre la necesidad del libro de texto para el estudio de la historia: "Para estudiar bien Historia se necesita un libro de texto". Fuente: elaboración propia.

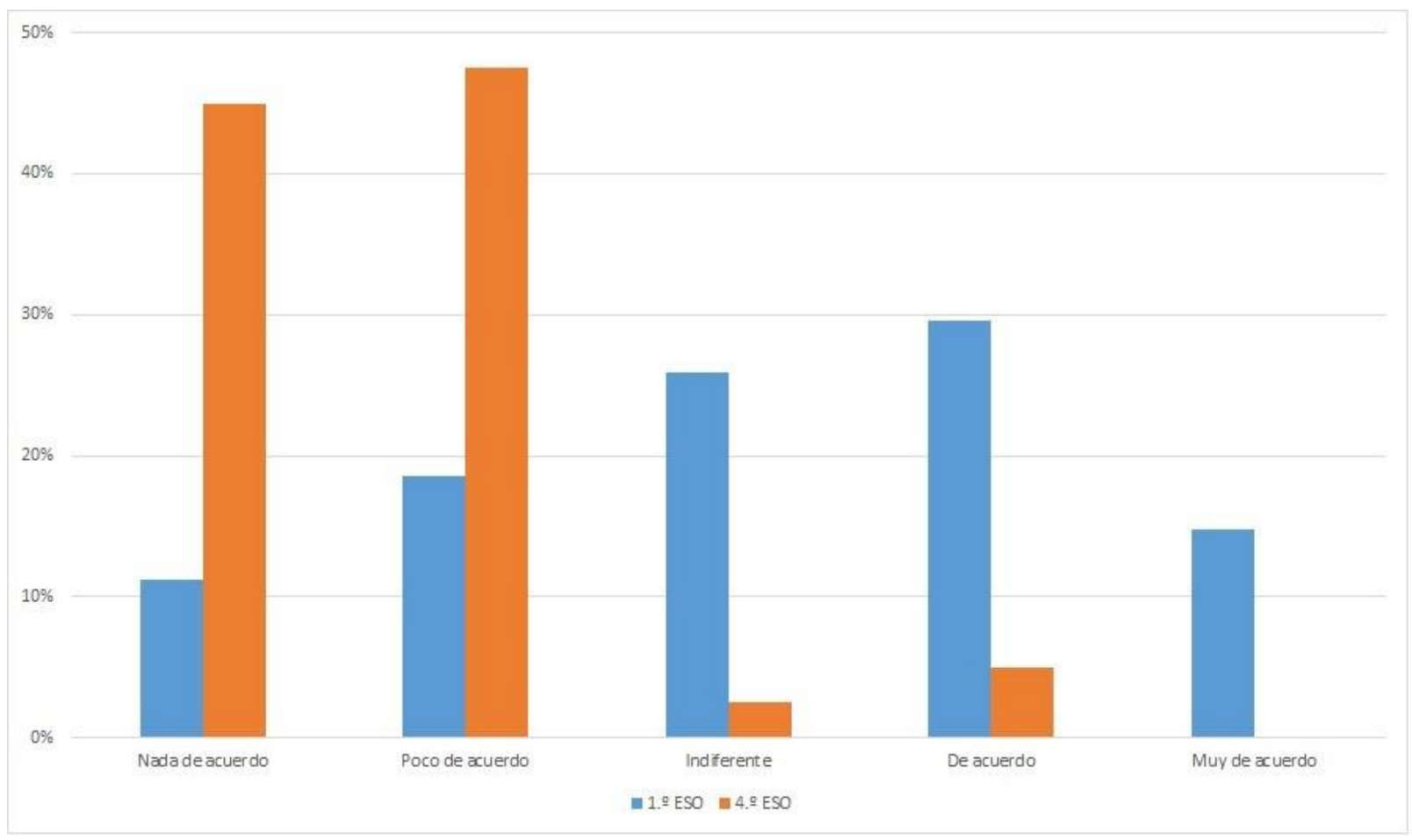

Figura 2. Percepciones sobre el carácter de los libros de texto en su relación con el relato histórico: "La Historia es, básicamente, lo que indican los libros de texto". Fuente: elaboración propia.

La concepción del relato histórico como una realidad definitiva y no abierta a interpretaciones es una de las notas características del código disciplinar según Cuesta (1997), cuyo aprendizaje se basa en el memorismo, que contribuye a la reproducción de representaciones naturalizadas (Peck y Seixas, 2008). También es una nota característica el carácter nacionalista del relato, especialmente advertido en el modelo de las historias generales. Sin tener esta investigación el 
objetivo central de desentrañar los discursos nacionalistas en el alumnado investigado, las narrativas han aportado elementos de conocimiento que permiten concluir que el prisma de la nación impregna un gran número de discursos aprehendidos, tanto en $1 .^{\circ}$ como en $4 .^{\circ} \mathrm{ESO}$, como se ha constatado en otras investigaciones (Sáiz, 2017). En el caso del alumnado más joven existe una clara interpretación anacrónica del pasado bajo la óptica de la realidad del Estado-nación actual de España, como se puede ver en estas dos citas: "Los romanos conquistaron toda la actual España menos el nordeste" (1 G.2); "Roma cuando llegó a Hispania mató a los pueblos que vivían aquí" (1C.15). Aunque en un sentido menos condicionado por esta identidad, una parte del alumnado de $4 .^{\circ}$ ESO valora positivamente las clases de Historia por contener contenidos propios de la historia nacional: "ha sido útil porque sabemos muchas más cosas de España de las que sabíamos" (4C. 15); "sí te recomiendo historia (...) porque es la historia del país donde vivimos" (4A.21). No hemos encontrado en el alumnado ejemplos de deconstrucción de estas identidades, asumidas de manera naturalizada, así como tampoco habían estado presentes en las entrevistas, analizadas en el punto anterior. Integrar esta perspectiva en el currículo real del aula supone una necesidad, no solo por suponer un aprendizaje de los rasgos del relato histórico, sino también para hacer frente a posibles posturas exclusivistas a nivel político por parte del alumnado, así como para desentrañar los mecanismos de dominación inherentes al currículo oficial.

En segundo lugar, es asimismo muy recurrente la concepción de la historia como maestra para la vida, siguiendo el tópico de Horacio, concebida esta como una suerte de instrumento para conocer el pasado y el presente con una función informadora (Gómez y Miralles, 2017), sin significar por ello una acción transformadora o cuestionadora. Esta tendencia ha sido también constatada por investigaciones empíricas recientes como la de Miguel-Revilla y Sánchez-Agustí (2018). De manera general, el alumnado responde afirmativamente cuando se le pregunta mediante un cuestionario si la historia le resulta útil, ubicándose más del $90 \%$ de las respuestas en los dos niveles analizados en las franjas que corresponden a estar de acuerdo o muy de acuerdo; sin embargo, un análisis cualitativo de las preguntas abiertas y de las narrativas ofrece matices más ricos, así como la comparación con otras preguntas cerradas más concretas. Por ejemplo, cuando se pide al alumnado valorar frases como "La asignatura de Historia es útil para la vida cotidiana" - "La asignatura de Historia no tiene gran aplicación en el día a día" los resultados confluyen en la misma idea y más de $60 \%$ del alumnado se muestra de acuerdo con la utilidad de esta materia escolar. No obstante, existe una gran diferencia entre la dispersión de los datos en $1 .^{\circ}$ ESO evidencia de una escasa reflexión sobre tal dimensión en el aula-, y la tendencia más clara de valorar la utilidad de la materia en $4 .^{\circ}$ ESO. Esta conclusión, presente también en otras cuestiones analizadas, se puede deber a la mayor madurez del alumnado de $4 .^{\circ} \mathrm{ESO}$, pero especialmente a una metodología didáctica en $11^{\circ}$ ESO menos orientada a poner de relieve la utilidad del pensamiento histórico, algo evidenciado por las docentes en las entrevistas realizadas.

No obstante, el análisis cualitativo permite observar salvedades significativas, como la del alumno 1C.4 que llega a afirmar en su narrativa que, "si sabemos leer un periódico y analizarlo, comprenderlo y situarlo en ese tiempo, entonces sabemos comprender la historia y conocerla". Este caso, no generalizable por la existencia de narrativas vagas y una dispersión considerable en los resultados de los cuestionarios de $1 .^{\circ} \mathrm{ESO}$, indica que la edad no supone un problema inabordable para tratar cuestiones complejas a nivel histórico y político. El alumnado, bien orientado y con unas estrategias didácticas diseñadas de acuerdo a unos fines determinados, es perfectamente capaz de desarrollar actitudes individuales en referencia al aprendizaje del tiempo histórico que supongan la adquisición de habilidades democráticas. 
En el nivel de $4 .^{\circ}$ ESO es posible encontrar una mayor cantidad de referencias en las narrativas que entroncan con una concepción de la historia como útil para la vida cotidiana, como puede ser la del alumno 4C.2 que señala que esta materia "puede servirte para no cometer los mismos errores", o la del caso 4C.3 que indica que "hay que conocer para no ser un ignorante fácil de manipular". La madurez del alumnado de 15 ○ 16 años no puede explicar por sí sola esta presencia de visiones más complejas sobre el pasado. Es necesario considerar que el profesorado de estos alumnos, tal y como se desprende de las entrevistas, valora la historia contemporánea presente en $4 .^{\circ}$ ESO como una materia más susceptible de relacionarse con el presente y tratar problemas actuales. También la mayor reflexión y elaboración del currículo en sentido didáctico por parte de las docentes en este curso redunda necesariamente en el desarrollo de visiones sobre el pasado mucho más complejas.

Esta última referencia nos puede servir para dar un salto cualitativo respecto a la representación de la historia como maestra para la vida hacia la concepción de esta como una disciplina que forma la ciudadanía crítica y democrática (Dewey, 1995; García y de Alba, 2009; Levstik y Barton, 2008). Resulta difícil encontrar referencias suficientes que nos permitan concluir que una gran mayoría del alumnado ha llegado a concebir el pensamiento histórico bajo este potencial. Además, la inclusión de una pregunta en el cuestionario que pedía la definición mediante un adjetivo de la clase de Historia por parte del alumnado ha permitido corroborar que son pocos los alumnos que describen las clases con adjetivos como "transformadora", "rompedora" o "política", y son una mayoría los que lo hacen con adjetivos más asépticos como "útil", "memorística" o "divertida". Esta tendencia se puede explicar por el peso del código disciplinar (Cuesta, 1997), la trayectoria de largo recorrido en la historia escolar del alumnado bajo paradigmas tradicionales en la enseñanza de la historia, así como por los rasgos ambivalentes de las clases recibidas en el curso analizado. No obstante, a continuación, analizaremos ejemplos concretos de aula para relacionarlos con lo expresado por las docentes y, así, dilucidar qué notas características de un modelo crítico que contribuya a la formación política del alumnado se puede observar en el aula.

\section{4. ¿Más allá de la "neutralidad excluyente" ?: enfoque crítico de la enseñanza de la Historia}

El modelo crítico de la enseñanza y el aprendizaje de la historia se caracterizan por una metodología activa y participativa, así como unos recursos y materiales que permitan concebir el relato histórico de manera problemática e incorporar diferentes perspectivas historiográficas (Segall et al., 2018). Además, coincidimos con autores como García y de Alba (2009), Levstik y Barton (2008), Audigier (1999) o Schugurensky (2012) en el sentido de que esta materia debe contribuir a la formación de habilidades y actitudes para la vida en democracia. Como comentábamos en páginas anteriores, las declaraciones de principios de las docentes entrevistadas comulgaban con estas ideas de manera evidente. No obstante, existe una distancia entre lo declarado y lo efectuado, algo investigado por otros autores como Merchán (2005) o en recientes investigaciones para otros niveles educativos (Boria y Parra, 2017). En esta investigación hemos constatado mediante la afirmación del cuestionario "Los exámenes se basan en explicar contenidos del libro de texto" cómo sigue habiendo un uso mayoritario de este recurso -si bien es mucho más utilizado como elemento central en 1. ${ }^{\circ}$ ESO-; recurso, por otro lado, criticado en las entrevistas por los problemas que presenta, si bien solo se diagnosticaban insuficiencias de tipo metodológico. Del mismo modo, la distancia entre las declaraciones de intenciones y lo que 
se hace realmente en el aula, se observa también en la afirmación "El profesor/a relaciona el pasado histórico con problemas actuales", en la cual se observan diferencias entre el grupo de M. E. $\left(1 .^{\circ} \mathrm{C}\right)$ en que sí se aborda este enfoque, y el de A. R. $\left(1 .^{\circ} \mathrm{G}\right)$ en el que mayoritariamente no, tendencia también observada con las respuestas de su grupo de $4 .^{\circ}$ ESO A. Las diferencias entre la práctica de docentes de un perfil semejante son evidentes, si bien en su discurso se observaban una serie de convicciones bastante convergentes.

Es, por tanto, en la práctica real de aula donde es posible tomar el pulso al carácter transformador de la enseñanza de la historia. El aula supone la auténtica "trastienda" (Wainermann, 1998) de la educación en la que se pueden observar y analizar las traducciones del currículo que hacen los docentes y la apropiación efectuada por parte del alumnado, considerado no como un receptáculo dispuesto a rellenar, sino como agentes capaces de interpretar el contenido histórico e, incluso, de llevar a cabo acciones de tipo político formal e informal (Arias-Cardona y Alvarado, 2015). Para ello, y reconociendo las limitaciones que se derivan de no haber podido emplear la observación de aula como instrumento de investigación, hemos optado por utilizar las narrativas del alumnado para establecer una división en dos tipologías de estrategias metodológicas empleadas en el aula, sistematizadas a partir de lo expresado por las docentes en relación: aquellas que surgen de la dinámica de aula de manera improvisada sin preparación por el docente, y aquellas concienzudamente programadas como actividades.

Respecto a las primeras, de acuerdo con las narrativas ha habido una presencia evidente en las aulas de temas actuales. Por ejemplo, la cuestión catalana estuvo presente por ser un tema conflictivo sobre el cual se generaron diferentes posicionamientos en los medios, hecho que permite comprobar que la escuela no se encuentra al margen de las controversias mediáticas y los problemas reales de la ciudadanía. Sin embargo, el tipo de respuesta por parte de la profesora A. R. se ubicó en el modelo de la imparcialidad neutral, señalado por López y Santidrián (2011), según el cual el docente trata de no ejercer ninguna influencia ideológica en el alumnado en aras de una pretendida neutralidad en el aula. La profesora A. R. lo abordó "sin dar mucho su opinión" (4C.4), de manera superficial y tangencial, tratándolo de manera factual e intencionalmente neutral, y sin un estudio complejo de las diferentes posiciones que permitirían abordar la cuestión de la multiperspectividad en la construcción del relato histórico (Wansink, Akkermann, Zuiker y Wubbels, 2018). Esta posición se enmarca en una postura evitativa (Corngold y Waddington, 2006, citado en Toledo, 2015) que ha sido detectada en otras investigaciones con docentes o futuros docentes (Gómez, Rodríguez y Mirete, 2018; Martínez, 2013; Valls, 2009) en las que se han observado tendencias a desvalorizar el potencial del debate como metodología, así como pretensiones de excesiva neutralidad, que no son sino una renuncia a abordar cuestiones controversiales con gran potencial educador (Goldberg y Savenije, 2018).

En un sentido semejante, se han encontrado referencias a debates en el aula sobre las condenas a los raperos como Valtónyc en 2017: "hablamos sobre este tema porque no nos parecían bien los años de condena" (4C.18). En el caso de la narrativa 4 C. 13 se va más allá porque se observa un razonamiento más maduro en términos históricos: "en la historia ha habido represión que se ha podido enlazar con hechos actuales y además persecución de raperos por expresar lo que piensan", aplicando aquí de manera autónoma un conocimiento adquirido (Lesh, 2011) y mostrando una capacidad de agencia del alumnado que trasciende las limitaciones que podría 
suponer un tratamiento escaso de las cuestiones controversiales por parte de su profesora. Aún así, coincidimos con lo expuesto por Pagés y Oller (2007) en su investigación acerca de las percepciones sobre el derecho y la justicia en el alumnado de $4 .^{\circ}$ ESO: se necesita una mayor formación del profesorado y del alumnado en cuestiones jurídicas que permita abordar estos temas más allá del sentido común y de las representaciones sociales hegemónicas.

Respecto a lo ocurrido en $1 .^{\circ}$ ESO, también han surgido espontáneamente debates acerca de la monarquía española actual, comparada con la de Roma en la cuestión de las funciones de los monarcas. Esta experiencia, ocurrida en clases de A. R., es descrita por ella de la siguiente forma: "se pusieron a debatir qué función tenía el monarca hoy en día y para qué servía (...) preguntaron que quién había votado al monarca". Sin embargo, se observa un tratamiento tangencial poco explotado en el cual la docente se muestra insegura. Ello supuso que detuviese el debate a los minutos de comenzar por temor a lo que pudiera comentar en casa el alumnado, ubicándose de nuevo en la posición de neutralidad excluyente (López y Santidrián, 2011), ejemplo a nuestro parecer de un rasgo propio de un modelo didáctico tradicional. A estas situaciones improvisadas de tratamiento crítico de la Historia se podrían sumar otros debates evidenciados en las narrativas (las diferencias entre ciudadanos de origen extranjero, el papel de la Iglesia o los sistemas políticos en sentido comparativo con la Grecia antigua), lo cual permite afirmar que el alumnado desea trabajar estos temas, como se ha comprobado por otros autores (Valls, 2009).

Se puede afirmar que existe en el caso analizado un temor al tratamiento de aspectos controversiales que, bajo nuestro punto de vista, pueden suponer un gran potencial para la educación política del alumnado y el desarrollo de habilidades como el respeto, la tolerancia y el pensamiento alternativo. La falta de formación de los docentes acerca del posicionamiento que es posible tener ante estas situaciones es uno de los factores explicativos (Toledo, 2015), si bien no pueden obviarse otros factores como la creciente preocupación del profesorado ante acusaciones de adoctrinamiento por parte de grupos sociales y políticos, así como una tradición en la educación española alejada de considerar el conflicto como algo positivo para el aprendizaje.

Sin embargo, sí hubo experiencias programadas que se podrían ubicar en un modelo más cercano al crítico, centradas sobre todo en $4 .^{\circ} \mathrm{ESO}$, dado que se ha llegado a advertir el empleo de las competencias clave con la finalidad de la alfabetización histórica (Sáiz, 2013a). Por un lado, se trabajó el tema del neofascismo mediante el visionado de la película La Ola (2008, Dennis Gansel) y se planteó la cuestión de si podría darse de nuevo una experiencia totalitaria, enlazando claramente con un enfoque ético de la disciplina (Rüsen, 2015), así como con una apuesta por la comparación entre pasado y presente (Muñoz, 2017). El alumnado da cuenta de la existencia de debates planificados en esta actividad ("hubo una comparación con la actualidad", 4C.7) y de la implicación a nivel personal ("en el trabajo se tenía que poner nuestra opinión personal sobre la película", 4C.1 1), por lo que esta experiencia indica una conexión clara con la actualidad (auge de la extrema derecha en Europa) y un tratamiento del pasado histórico que huye del relato cerrado del manual (Viñao, 2003).

Como ejemplos de otras experiencias, se empleó el itinerario didáctico de la Valencia republicana estableciendo comparaciones con la actualidad de la ciudad en un trabajo vivencial (Cantó y Fuertes, 2015), se debatió sobre la vigencia de la Constitución Española empleando un 
dosier de trabajo de la España entre 1931-2018, y se trabajó con noticias actuales sobre el islamismo, el desarme de ETA o el régimen norcoreano. Estos ejemplos dan cuenta de la posibilidad real de abordar el currículo de un modo abierto y problemático.

No obstante, sin ser la línea central de la investigación, creemos interesante resaltar que no se han evidenciado referencias a un tratamiento conflictivo del pasado reciente de España de manera explícita acerca de la Guerra Civil y el Franquismo, a pesar de haber sido incluidos estos temas en los enunciados de las narrativas de manera explícita. Resulta también de gran interés observar la decisión docente de tratar un tema conflictivo en el contexto alemán que tiene su traducción directa con la actualidad (el auge de la extrema derecha en Europa), pero no haber podido detectar una actividad que, de manera tan específica, aborde estos problemas en el caso español, como podría haber sido el tratamiento de la memoria democrática, los lugares de memoria o la existencia de fosas comunes en España. Las dificultades en el tratamiento didáctico de estos temas, de gran relevancia para la formación política en un contexto determinado por parte del alumnado, requerirá de investigaciones específicas a pesar de que ya se han producido aportaciones relevantes en esta línea (Fuertes, 2018; Valls, 2009; Valls, Parra y Fuertes, 2017).

\section{Reflexiones finales}

Tras haber realizado los diferentes análisis a partir de los instrumentos de investigación planteados, es útil retomar las hipótesis de partida con la finalidad de constatarlas o rechazarlas. La hipótesis 1 planteaba que los discursos de las docentes entrevistadas sobre su práctica educativa no se orientaban a educar en el marco de una ciudadanía crítica y democrática al alumnado. Hemos podido comprobar que resulta parcialmente cierta, dado que existe una disonancia clara entre el modelo que preconizan las docentes, ubicado parcialmente en un paradigma crítico (García, 2000; Pozo et al., 1989) y la práctica real de aula, analizada desde el punto de vista del alumnado. Estudiar el aula desde estas dos miradas, aun con evidentes limitaciones por tratar con discursos verbalizados con posibles sesgos, sin haber realizado una observación de aula, ha supuesto tener una mirada más compleja del hecho educativo. No obstante, es cierto que hemos podido encontrar experiencias didácticas críticas y reflexivas sobre el conocimiento histórico que enlazan con la tercera dimensión sobre los usos y finalidades de la materia, vinculada a educar en una ciudadanía crítica mediante las controversias y la participación del alumnado. No obstante, sería positivo generalizarlas mediante una coordinación docente, su extensión a todo el currículum aprovechando sus grietas, y convirtiendo las experiencias espontáneas de debate en unidades didácticas programadas. No se ha observado una presencia explícita y programada de diferentes visiones historiográficas, tales como la historia sociocultural o la historia de género, que enriquecerían enormemente el aprendizaje de la historia y facilitarían el desarrollo de habilidades deseables en una sociedad democrática. En la misma línea, consideramos que no se han aprovechado de manera óptima las oportunidades para lograr un aprendizaje del tiempo histórico desde una visión multiperspectiva. Tampoco se ha puesto de relieve en la práctica de aula, aunque sí levemente en las entrevistas, un cuestionamiento de las identidades naturalizadas en el currículo, como es el caso de las nacionales. Consideramos que la excesiva centralidad en el uso del libro de texto, con los matices observados, así como la falta de una programación didáctica que aborde de manera decidida los problemas socialmente relevantes por medio de las competencias históricas, impiden una construcción crítica del conocimiento histórico. Asimismo, el temor a las acusaciones de adoctrinamiento $o$ la falta de formación sobre el posicionamiento docente suponen un freno 
importante al potencial que estas docentes tienen de acuerdo con sus principios declarados. Existe igualmente una gran diferencia entre lo realizado -y lo que se considera realizable- en $4 .^{\circ} \mathrm{ESO}$ y lo que ocurre en las aulas de $1 .^{\circ}$ ESO, aspecto que debería investigarse con mayor detenimiento.

La hipótesis 2 señalaba que el alumnado analizado mantenía una concepción limitada de la potencialidad del saber histórico en su contribución a la educación política. Consideramos que también es parcialmente cierta por la presencia continua de notas características del código disciplinar de la materia (Cuesta, 1997) que, a nuestro juicio, limitan la conformación de una ciudadanía activa. Las referencias al conocimiento histórico como saber útil para la transformación del presente no son mayoritarias; aunque sí aparecen en algunos alumnos que reflexionan sobre la función social de la historia, el papel del disenso, la comparación de fuentes y la posibilidad de enfocar un mismo hecho desde puntos de vista distintos, mostrando una posible capacidad de acción en el alumnado que debe ser aprovechada. Estas reflexiones llegan en el momento en que, desde el aula, se opta por abordar la materia desde un sentido crítico, o surgen debates de manera espontánea, por lo que profundizar en esta metodología permitiría llegar a reflexiones más complejas sobre la utilidad de la historia enseñada, así como contribuir a la educación política de la juventud, compromiso clave de la escuela (Marí et al., 2016, p. 66), de acuerdo con lo expresado en el Informe Juventud en España de 2016.

Esta investigación, de tipo mixto, uniendo la dimensión cuantitativa y la cualitativa (Bisquerra, 1989; Van Maanen, 1983), no pretende ser generalizable por el carácter reducido de la muestra y por las características propias del estudio de campo, pero sí abrir un abanico de posibilidades de investigación tras haber examinado con profundidad un contexto real de aula, tanto desde el docente como desde el discente, siguiendo las ideas del profesional reflexivo desde la acción (Giroux, 1990; Silva, 2001). Haber puesto el foco en la enseñanza de dos docentes al inicio de su carrera profesional, con una formación similar a nivel disciplinar y educativo, permite abrir una línea de indagación que requerirá mayores análisis y una muestra más extensa. Nos referimos al cambio en las rutinas profesionales y en la adopción de modelos didácticos críticos que supone la formación del Máster de Profesor/a de Educación Secundaria, cursado por ambas docentes. Si bien esta formación mejoró mucho la existente con anterioridad a su implantación, se han observado importantes carencias formativas en referencia a la concepción de la disciplina que defendemos en esta investigación. Por ello, esta investigación ha abierto perspectivas de futuro realmente interesantes que envuelven el objeto de estudio de la formación política del alumnado desde el estudio de la historia. Estas líneas de trabajo son la cuestión del posicionamiento docente ante el binomio neutralidad/beligerancia; la presencia de los libros de texto en el aula como hándicap para la innovación; la influencia real de la normativa educativa en las aulas; la transformación de las rutinas docentes por parte de la formación inicial del profesorado; o el tratamiento del pasado traumático como medio para la educación política y democrática del alumnado.

\section{Bibliografía}

Albert, M. J. (2006). La investigación educativa. Claves teóricas. Madrid: Mc Graw Hill.

Álvarez, J. (2017). Dioses útiles: nacionales y nacionalismos. Barcelona: Galaxia Gutenberg.

Anderson, B. (1993). Comunidades imaginadas. Reflexiones sobre el origen y la difusión del nacionalismo. México: Fondo de Cultura Económica. 
Angulo, J. F. y Redon, S. (2017). Métodos mixtos: convergencia metodológica y divergencia epistemológica. En S. Redon y J. F. Angulo (coords.), Investigación cualitativa en educación (pp.327-353). Buenos Aires: Miño y Dávila.

Arias-Cardona, A. M. y Alvarado, S. V. (2015). Jóvenes y política: de la participación formal a la movilización informal. Revista latinoamericana de ciencias sociales, niñez y juventud, 13(2), 581-594. doi: $10.11600 / 1692715 \times .1322241014$

Audigier, F. (1999). L'éducation à la citoyenneté. París: INRP.

Bel, J. C., Colomer, J. C. y Valls, R. (2019). Alfabetización visual y desarrollo del pensamiento histórico: actividades con imágenes en manuales escolares. Educación XXI: Revista de la Facultad de Educación, 22(1), 353-374. doi: 10.5944/educxx1.20008

Billig, M. (1995). Nacionalismo banal. Madrid: Capitán Swing.

Bisquerra, R. (1989). Métodos de investigación educativa: guía práctica. Barcelona: CEAC.

Boria, S. y Parra, D. (2017). Cambios y permanencias en la concepción de la historia de estudiantes de magisterio de la Universitat de València. En R. Martínez Medina, R. GarcíaMorís y C. R. García Ruiz (comp.), Investigación en didáctica de las ciencias sociales. Retos, preguntas y líneas de investigación (pp. 34-41). Córdoba: Universidad de Córdoba.

Cantó, J. y Fuertes, C. (2015). La tècnica de l'itinerari didàctic en la formació inicial del professorat: reconstrucció d'una experiència. @tic. Revista d'innovació educativa, 14, 23 30. doi: $10.7203 /$ attic. 14.4417

Carretero, M., Castorina, J. A., Sarti, M., Van Alphen, F. y Barreiro, A. (2013). La construcción del conocimiento histórico. Propuesta Educativa, 39(I), 13-23.

Carretero, M., Rosa, A. y González, E. F. (2006). Enseñar historia en tiempos de memoria. En M. Carretero, A. Rosa y M. F. González (comp.), Enseñanza de la historia y memoria colectiva (pp. 11-36). Buenos Aires: Paidós.

Chevallard, Y. (1997). La transposición didáctica. Del saber sabio al saber enseñado. Buenos Aires: Aique.

Cuesta, R. (1997). Sociogénesis de una disciplina escolar. Barcelona: Pomares-Corredor.

Cuesta, R. (2011). Historia con memoria y didáctica crítica. Con-ciencia social: anuario de didáctica de la geografía, la historia y las ciencias sociales, 15, 15-30.

Cuesta, R., Mainer, J. y Mateos, J. (2008). La genealogía, historia del presente y didáctica crítica. En J. Mainer (coord.), Pensar críticamente la educación escolar. Perspectivas y controversias historiográficas (pp. 51 -82). Zaragoza: Publicaciones de la Universidad de Zaragoza.

Dewey, J. (1995). Democracia y educación: una introducción a la filosofía de la educación. Madrid: Morata.

Díaz-Chorne, L. y Díaz-Catalán, C. (2016). Captar la participación política transnacional de la juventud: más allá de la participación electoral. Revista de Estudios de Juventud, 113,173 188.

Estellés, M. (2015). Lo que no vemos sobre la educación ciudadana en la formación del profesorado: supuestos y sobreentendidos. En A. M. Hernández, C. R. García y J. L. de la Montaña (coords.), Una enseñanza de las ciencias sociales para el futuro: Recursos para 
trabajar la invisibilidad de personas, lugares y temáticas (pp. 483-489). Cáceres: Universidad de Extremadura. Servicio de Publicaciones. Asociación Universitaria de Profesores de Didáctica de las Ciencias Sociales.

Febvre, L. (1982). Combates por la historia. Barcelona: Ariel.

Fernández, C., García, O. y Galindo, E. (2017). Escuela o barbarie. Entre el neoliberalismo salvaje y el delirio de la izquierda. Madrid: Akal.

Franklin, M. (2004) Voter Turnout and the Dynamics of Elector Competition in Established Democracies since 1945. Cambridge: Cambridge University Press.

Freire, P. (1975). Pedagogía del oprimido. Madrid: Siglo XXI.

Freire, P. (2009). La educación como práctica de la libertad. Madrid: Siglo XXI.

Fuertes, C. (2016). La Influencia sobre los Estudiantes del Profesorado Crítico del Tardofranquismo: el Caso de las Ciencias Sociales. Social and Education History, 5(2), 188 194. doi: $10.17583 /$ hse.2016.1996

Fuertes, C. (2018). La dictadura franquista en los manuales escolares recientes. Una revisión crítica. Revista Historia Autónoma, 12, 279-297. doi: 10.15366/rha2018.12.015

Funes, M. J. (2006). De lo visible, lo invisible, lo estigmatizado y lo prohibido. Revista estudios de juventud, 75, 11-27.

Fuster, C. (2016). Pensar históricamente la evaluación en la PAU de Historia de España (tesis de doctorado). Universitat de València, València, España.

García, F. (2000). Un modelo didáctico alternativo para transformar la educación: el Modelo de Investigación en la Escuela. Scripta Nova, Revista Electrónica de Geografía y ciencias sociales, 4(64). Recuperado de: http://www.ub.edu/geocrit/sn-64.htm

García, F. y de Alba, N. (2009). Educar para la Participación Ciudadana. Análisis de las Dificultades del Profesorado a Partir de la Experiencia del Programa Parlamento Joven. En R. M. Ávila Ruiz, B. Borghi e I. Mattozzi (coords.), L'educazione Alla Cittadinanza Europea e la Formazione Degli Insegnanti. Un Progetto Educativo Per la "Strategia di Lisbona" (pp. 515-521). Vol I. Bolonia: Pàtron.

Gibbs, G. (2012). El análisis de datos cualitativos en Investigación Cualitativa. Madrid: Morata.

Giroux, H. (1990). Los profesores como intelectuales: hacia una pedagogía crítica del aprendizaje. Barcelona: Paidós Ibérica.

Goldberg, T. y Savenije, G. M. (2018). Teaching Controversial Historical Issues. En S. Alan y L. McArthur (coords.). The Wiley International Handbook of History Teaching and Learning (pp. 503-526). Nueva York: Wiley Blackwell.

Gómez, C. J. y Miralles, P. (2017). Los espejos de Clío. Usos y abusos de la Historia en el ámbito escolar. Madrid: Sílex.

Gómez, C. J. y Rodríguez, R. A. (2017). La historia como materia formativa. Reflexiones epistemológicas e historiográficas. Revista de historiografía, 27, 265-286. doi: $10.20318 /$ revhisto.2017.3974

Gómez, C. J. y Sáiz, J. (2017). Narrative inquiry and historical skills. A study in teacher training. Revista Electrónica de Investigación Educativa, 19(4). doi: 10.24320/redie.2017.19.4.910 
Gómez, C. J., Cózar, R. y Miralles, P. (2014). La enseñanza de la historia y el análisis de los libros de texto. Construcción de identidades y desarrollo de competencias. Ensayos. Revista de la Facultad de Educación de Albacete, 29(1), 1-25. doi: 10.18239/ensayos.v29i1.532

Gómez, C. J., Rodríguez, R. A. y Mirete, A. B. (2018). Percepción de la enseñanza de la historia y concepciones epistemológicas. Una investigación con futuros maestros. Revista Complutense de Educación, 29(1), 237-251. doi: 10.5209/RCED.52233

Grant, S. G. (2018). Teaching Practices in History Education. En S. Alan y L. McArthur (coords.), The Wiley International Handbook of History Teaching and Learning (pp. 419-448). Nueva York: Wiley Blackwell.

Haste, H. y Bermúdez, A. (2017). The Power of Story: Historical Narratives and the Construction of Civic Identity. En M. Carretero, S. Berger y M. Grever (eds.), Palgrave Handbook of Research in Historical Culture and Education (pp. 427-448). Londres: Palgrave Macmillan.

Heimberg, C. (2009). L'appentissage de l'histoire pour contribuir à une citoyyenneté européene critique et ouverte: un point de vue "extracommunnautaire". En R. M. Ávila, B. Borghi e I. Mattozzi (coords.), L'educazione alla cittadinanza europea e la formazione degli insegnanti. Un progetto educativo per la "Strategia di Lisbona" (pp. 309-316). España: Pàtron.

Hobsbawm, E. y Ranger, T. (2002). La invención de la tradición. Barcelona: Crítica.

Holloway, I. (1997). Basic Concepts for Qualitative Research. Londres: Wiley-Blackwell.

Hroch, M. (2001). La naturalesa de la nació. Catarroja: Afers.

Injuve (2017). Sondeo de opinión y situación de la gente joven. Jóvenes, Participación y Cultura Política. Ministerio de Sanidad, Servicios Sociales e Igualdad.

Jodelet, D. (2000). Representaciones sociales: contribución a un saber sociocultural sin fronteras. En D. Jodelet y A. Guerrero, Develando la cultura. Estudios en representaciones sociales (pp. 7-30). México: Facultad de Psicología-UNAM.

Lee, P. y Ashby, R. (2000). Progression in Historical Understanding among students ages 7-14. En P. N. Stearns, P. Seixas y S. Wineburg (et al.), Knowing, teaching and learning history. National and International perspectives (pp. 199-222). Nueva York: NYU Press.

Lesh, B. (201 1). Why won't you just tell us the answer?" Teaching historical thinking in grades 7-12. Portland: Stenhouse.

Levstik, L. (2014). What Can History And The Social Sciences Contribute To Civic Education? En J. Pagès y A. Santisteban (eds.), Una mirada al pasado y un proyecto de futuro. Investigación e innovación en didáctica de las ciencias sociales (pp. 43-52). Barcelona: AUPDCS.

Levstik, L. y Barton, K.C. (2008). Researching History Education: Theory, Method, and Context. Nueva York- Londres: Routledge.

Lomas, C. (2011). Lecciones contra el olvido: memoria de la educación y educación de la memoria. Barcelona: Octaedro.

López, R. (2014). La LOMCE y la competencia histórica. Ayer, 94, 273.285.

López, R. y Santidrián, V. (2011). Los "conflictos sociales candentes" en el aula. Íber. Didáctica de las Ciencias Sociales, Geografía e Historia, 69, 8-20. 
Marí, R. M., Moreno, R., e Hipólito, N. (2016). Educación y ciudadanía. Propuestas educativas desde la controversia. Foro de Educación, 14(20), 49-69. doi: $10.14516 /$ fde. 2016.014 .020 .005

Martínez, R. (2013). Profesores entre la historia y la memoria: un estudio sobre la enseñanza de la transición dictadura-democracia en España (tesis de doctorado). Universidad de Valladolid, Valladolid, España.

Martínez, R., Conejo, F., y López, R. (2011). La evaluación en las P.A.U. de historia: Un estudio de la transición a la democracia en España. En P. Miralles, S. Molina y A. Santiesteban (coords.), La evaluación en el proceso de enseñanza y aprendizaje de las Ciencias Sociales (pp. 259268). Murcia: Asociación Universitaria de Profesorado de Didáctica de las Ciencias Sociales.

Mattozzi, I. (1999). La transposición del texto historiográfico: un problema crucial de la didáctica de la historia. Revista de Teoría y Didáctica de las Ciencias Sociales, 4, 27-56.

McCully, A. W. y Barton, K. C. (2007). Teaching Controversial Issues where controversial issues really matter. Teaching History, 127, 13-19.

Merchán, F. J. (2005). Enseñanza, examen y control: profesores y alumnos en la clase de historia. Barcelona: Octaedro.

Miguel-Revilla, D., y Sánchez-Agustí, M. (2018). Modelos de conciencia histórica en el alumnado de educación secundaria: Tradición, simbología y contextualización en torno a los restos del franquismo. Panta Rei: revista de ciencia y didáctica de la historia, 8, 119-142. doi: $10.6018 /$ pantarei/2018/1

Montaña, J. L. (2014). Didáctica de la Historia y profesorado en formación: análisis de concepciones y nuevos paradigmas para una enseñanza-aprendizaje de la Historia. En J. Pagès y Blanch y A. Santisteban (coords.), Una mirada al pasado y un proyecto de futuro: investigación e innovación en didáctica de las ciencias sociales. Vol. 2. (pp. 551-558). Barcelona: Universitat Autònoma de Barcelona, Servei de Publicacions.

Montaña, J. L. (2015). Didáctica de la historia, historiografía y la visibilización de temas, grupos sociales y personas en la enseñanza-aprendizaje de la historia. En A. M. Hernández, C. R. García y J. L. de la Montaña (coords.), Una enseñanza de las ciencias sociales para el futuro: Recursos para trabajar la invisibilidad de personas, lugares y temáticas (pp. 907-915). Cáceres: Universidad de Extremadura. Servicio de Publicaciones. Asociación Universitaria de Profesores de Didáctica de las Ciencias Sociales.

Moscovici, S. (comp.) (1986). Psicología Social II. Pensamiento y vida social. Psicología social y problemas sociales. Barcelona: Paidós.

Moscovici, S. y Hewstone, M. (1986). De la ciencia al sentido común. En S. Moscovici (comp.), Psicología social II. Pensamiento y vida social. Psicología social y problemas sociales (pp. 679$711)$. Barcelona: Paidós.

Muñoz, E. (2017). Las relaciones pasado-presente en la enseñanza de la Historia: en busca del sentido de los aprendizajes históricos. Enseñanza de las Ciencias Sociales, 16, 103-114.

Nash, G. B., Crabtree, C. A. y Taskforce, N. S. (1996). National Standards for History: Basic Edition. Los Ángeles: Natl Center for History in. 
Pagès, J. (2005). Educación cívica, formación política y enseñanza de las ciencias sociales, de la geografía y de la historia, íber. Didáctica de las Ciencias Sociales, Geografía e Historia, 44, 45-56.

Parés, M. y Subirats, J. (2016). Muy jóvenes, jóvenes y menos jóvenes. El lío de la juventud y la política. Revista de Estudios de Juventud, 11 4, 45-58.

Parra, D. (2010). La importancia de las tendencias historiográficas en la concepción de la historia y su didáctica para futuros maestros. En R. M. Ávila, M. P. Rivero y P. L. Domínguez (coords.), Metodología de investigación en Didáctica de las Ciencias Sociales (pp. 257-262). Zaragoza: Institución Fernando el Católico.

Parra, D. (2013). La conceptualización de la Historia escolar y sus implicaciones didácticas. Un estudio a partir del recuerdo de estudiantes de BUP. Didáctica de las Ciencias Experimentales y Sociales, 27, 3-21. doi: 10.7203/DCES.27.2653

Parra, D. (2019). Representación de la historia escolar y crítica del consenso del sentido común. En D. Parra y C. Fuertes (coords.), Reinterpretar la tradición, transformar las prácticas. Ciencias Sociales para una educación crítica (pp. 73-98). Valencia: Tirant lo Blanch.

Peck, C. y Seixas, P. (2008). Benchmarks of Historical Thinking: First Steps. Canadian Journal of Education, $31(4)$, 1015-1038.

Pozo, J. I., Asensio, M. y Carretero, M. (1989). Modelos de aprendizaje-enseñanza de la Historia. En M. Carretero, J. I. Pozo, y M. Asensio (comps.), La enseñanza de las ciencias sociales (pp. 211 -240). Madrid: Visor.

Prats, J. (1997). La selección de contenidos históricos para la educación secundaria. Coherencia y autonomía respecto a los avances de la ciencia histórica. Íber. Didáctica de las Ciencias Sociales, Geografía e Historia, 12 . Recuperado de http://www.ub.edu/histodidactica/index.php?option=com content\&view=article\&id=79:1 a-seleccion-de-contenidos-historicos-para-la-educacion-secundaria-coherencia-yautonomia-respecto-a-los-avances-ciencia-historica\&catid=24:articuloscientificos\&ltemid $=118$.

Ramos, F. J. (2016). Educación y ciudadanía: la necesidad de generar espacios para la discrepancia y el diálogo. Foro de Educación, 14 (20), 13-19. doi: $10.14516 /$ fde.2016.014.020.002

Romero, J. (2018). La historia del currículum como fuente para la Didáctica de las Ciencias Sociales. Revista de Investigación en Didáctica de las Ciencias Sociales, 3, 103-1 18.

Rozada, J. $M^{a}$ (1997). Formarse como profesor. Ciencias Sociales, Primaria y Secundaria Obligatoria. Madrid: Akal.

Ruiz, J. I. (2009). Metodología de la investigación cualitativa (4 $4^{a}$ Ed.). Bilbao: Universidad de Deusto.

Rüsen, J. (2005). History: Narration, Interpretation, Orientation. Nueva York: Berghahn.

Rüsen, J. (2015). Teoria da História. Uma teoría da história como ciencia. Curitiba (Brasil): Universidade Federal do Paraná.

Saha, L. J., Print, M. y Edwards, K. (eds.) (2007). Youth and Political Participation. Rotterdam, Sense. 
Sáiz, J. (2011). Actividades de libros de texto de Historia, competencias básicas y destrezas cognitivas, una difícil relación: análisis de manuales de $1^{\circ}$ y $2^{\circ}$ de ESO. Didáctica de las ciencias experimentales y sociales, 25, 37-64.

Sáiz, J. (2013a). Alfabetización histórica y competencias básicas en libros de texto de historia y en aprendizajes de estudiantes. Didáctica de las Ciencias Experimentales, 27, 43-66.

Sáiz, J. (2013b). El tratamiento de las competencias básicas en los actuales libros de texto de historia en secundaria. Limitaciones y propuestas de mejora. Íber. Didáctica de las Ciencias Sociales, Geografía e Historia, 74, 52-61.

Sáiz, J. (2017). Pervivencias escolares de narrativa nacional española: Reconquista, Reyes Católicos e Imperio en libros de texto de historia y en relatos de estudiantes. Historia y Memoria de la Educación, 6, 165-201. doi: 10.5944/hme.6.2017.17137

Schugurensky, D. (2012). Civic engagement and participatory governance. En R. Kelly (ed.), Civic Engagement: 100th Arizona Town Hall (pp. 72-79). Phoenix: Arizona Town Hall.

Segall, A., Trofanenko, B. M. y Schmitt, A. J. (2018). Critical Theory and History Education. En S. Alan y L. McArthur (coords.), The Wiley International Handbook of History Teaching and Learning (pp. 283-309). Nueva York: Wiley Blackwell.

Seixas, P. y Morton, T. (2013). The big six historical thinking concepts. Nelson: Toronto.

Silva, T. (2001). Espacios de identidad: nuevas visiones sobre el currículum. Barcelona: Octaedro.

Starkey, H. (2012). Human Rights and Education. En J. Banks (ed.), Encyclopedia of Diversity in Education (pp. $1115-1118$ ). Londres: SAGE.

Strauss, A. L., y Corbin, J. (2002). Bases de la investigación cualitativa: técnicas y procedimientos para desarrollar la teoría fundamentada. Medellín: Universidad de Antioquia.

Thiesse, A-M. (1999). La creación de las identidades nacionales: Europa: siglos XVIII-XX. Madrid: Ensenada de Ézaro.

Toledo, M. I. (2015). Enseñanza de "temas controversiales" en la asignatura de Historia, desde la perspectiva de los profesores. Estudios pedagógicos, 41(1), pp. 21-28.

Trepat, C. A. (2015). La historia en la LOMCE. ESO y Bachillerato. Íber. Didáctica de las Ciencias Sociales, Geografía e Historia, 79, 49-59.

Trilla, J. (1992). El profesor y los valores controvertidos: neutralidad y beligerancia en la educación. Barcelona: Paidós.

Trilla, J. (1995). Educación y valores controvertidos. Elementos para un planteamiento normativo sobre la neutralidad en las instituciones educativas. Revista iberoamericana de Educación, 7 , 93-120.

Tutiaux Guillon, N. (2003). Los fundamentos de una investigación sobre la concepción de las finalidades cívicas y culturales del profesorado de geografía e historia. Objetivo de esta etapa. Enseñanza de las Ciencias Sociales, 2, 27-35.

Valls, R, Parra, D. y Fuertes, C. (2017). Los temas históricos conflictivos y su abordaje escolar: un ejemplo español. Clío \& Asociados. La historia asociada, 25, 8-21.

Valls, R. (2009). Historia y memoria escolar: Segunda república, guerra civil y dictadura franquista en las aulas (1938-2008). Valencia: Publicacions de la Universitat de València. 
Valls, R. y Colomer, J. C. (2018). El modelo de las historias generales. En V. Peris, D. Parra y X. M. Souto (coord.), Repensamos la geografía e historia para la educación democrática (pp. 23-26). Valencia: Nau Llibres.

Van Maanen, J. (1983). Qualitative methodology. Beverly Hills: Sage.

Viñao, A. (2003). La educación en valores y los libros de texto. Ceapa, 76, 20-22.

Wainermann, C. (1998). Introducción: acerca de la formación de investigadores en ciencias sociales. En C. Wainerman y R. Sautu (coords.), La trastienda de la investigación (pp. 15-40). Buenos Aires: Belgrano.

Wansink, B., Akkerman, S., Zuiker, I. y Wubbels, T. (2018). Where Does Teaching Multiperspectivity in History Education Begin and End? And Analysis of the Uses of Temporality. Theory \& Research in Social Education, 46, 495-527. doi: 10.1080/00933104.2018.1480439

Ydesen, C. y Andreasen, K. E. (2019). Los antecedentes históricos de la cultura evaluativa global en el ámbito de la educación. Foro de Educación, 17(26), 1-24. doi: 10.14516/fde.710 


\section{Panta Rei}

PANTA REl es una revista digital de investigación orientada a la Historia y la Didáctica de la Historia. Su principal objetivo es la transmisión del conocimiento científico, dando una oportunidad también a los jóvenes investigadores que quieren abrirse camino en el estudio de las ciencias humanas y sociales. Se compone de estudios originales relacionados con la disciplina histórica así como su didáctica y difusión. Las diferentes secciones que componen la revista son: artículos de investigación, entrevistas a profesionales, recensiones de monografías de actualidad y crónicas de congresos o eventos científicos relevantes.

Todos los artículos publicados son objeto de un proceso de revisión a cargo de un mínimo de dos evaluadores, que se consideran expertos en el ámbito temático del artículo propuesto. Nuestro deseo es poder ofrecer unos contenidos rigurosos, de calidad y de interés.

El CEPOAT (Centro de Estudios del Próximo Oriente y la Antigüedad Tardía de la Universidad de Murcia) es la institución encargada de la coordinación y gestión de la revista, desde donde anualmente se lanzará la convocatoria para aquellos que estén interesados en publicar sus trabajos, siempre relacionados con la Historia y la Didáctica de la Historia.

PANTA REI is a digital journal focused on History and Teaching History. Its main objective is the transmission of scientific knowledge by giving also an opportunity to young researchers who want to make their way in the study of human and social sciences. It is composed by original studies related to History, as well as its didactics and promotion. The different sections of this journal are: research articles, interviews to professionals, recensions on monographs about current issues and reports about congresses or relevant scientific events.

All the articles published are subject to a revision process carried out by a minimum of two reviewers who are considered to be experts in the field of the article proposed. Our wish is to offer rigorous contents with quality and being of interest to the reader.

CEPOAT (Centre of Studies of the Middle East and Late Antiquity of the University of Murcia) is the institution in charge of the coordination and management of this journal. This is the centre from where the call for papers will be launched annually for all the people interested in publishing their papers, always related to History and Teaching History. 


\section{Normas de publicación}

El autor se compromete a enviar trabajos originales, que no se encuentren publicados en otras revistas ni en otros idiomas. Así mismo, el mismo artículo no podrá ser presentado en otras revistas mientras dure el proceso de evaluación.

\section{Envío y presentación de originales}

Las normas de edición y forma de envío de artículos a la revista se pueden consultar en https://revistas.um.es/pantarei/

Para la redacción de los trabajos se tendrá en cuenta el Manual de la American Psychological Association, en su $7 .^{a}$ edición. La extensión máxima de los trabajos será de 25 páginas. La revista acepta originales escritos en español o inglés.

\section{Proceso de valoración y evaluación}

Una vez recibidos los trabajos, la Revista realizará una primera valoración. Si el trabajo enviado se ajusta a las normas de presentación propuestas, la temática es coincidente con la línea editorial de la revista y posee la calidad científica necesaria, será remitido al consejo asesor para una primera evaluación. Si no es así en este primer paso se puede rechazar directamente los documentos que incumplan claramente la línea editorial.

Será el Consejo Asesor quien indique a la revista la originalidad, relevancia, estructura, redacción, aparato bibliográfico, etc. del trabajo enviado y, para ello, se designará a dos revisores expertos externos que evaluarán cada uno de los trabajos, que pueden formar parte (o no) de este Consejo Asesor. La selección de los revisores se ajustará a la temática y características metodológicas del trabajo. El nombre y filiación de los autores serán eliminados del trabajo para su revisión, así como los revisores actuarán de manera anónima y confidencial.

Los revisores deberán rellenar un informe de evaluación que centrará su atención en aspectos tales como características formales, originalidad y novedad de los trabajos, relevancia de las propuestas y los resultados, calidad metodológica y validez científica.

Una vez terminado el proceso se decidirá la aceptación o no de los mismos y su publicación en el número que sea pertinente, así como las modificaciones susceptibles de ser realizadas para su final publicación. Dicha notificación se enviará únicamente por correo electrónico, en un plazo máximo de seis meses. 


\section{Publishing rules}

The author is committed to submit original papers not having been published in other reviews or in other languages. In this way, it is not allowed for the same paper to be presented in other reviews during the evaluation process.

\section{Submission and presentation of originals}

The editing rules and the guidelines for the submission of papers can be consulted at https://revistas.um.es/pantarei/

The seventh edition of the Manual of the American Psychological Association will be taken into account for the writing of the papers. The length of the submitted papers will not exceed the 25 pages. The journal accepts originals written in Spanish or English.

\section{Examination and assessment process}

The Journal will submit the papers to a first examination once received. If the paper follows the presentation guidelines, the subject agrees with the editorial line of this journal, and possess the scientific quality required, it will be sent to the advisory council for a first assessment. If not, the documents which clearly fail to complete the editorial line may be rejected straightaway in this first step.

The Advisory Council will indicate the originality, relevance, structure, writing, bibliography, etc. of the text to the journal; for this purpose, two outside experts will be designated to review the papers; these experts can be (or not) part of this Advisory Council. The selection of the experts will adjust to the subject and methodological characteristics of the paper. Name and affiliation of the author will be eliminated from the text for its review, in this way experts will act anonymously and confidentially.

The experts will fill out an assessment report which will focus on aspects such as formal characteristics, originality and novelty of the papers, relevance and results of the proposal, methodological quality and scientific validity.

Once the process is finished, the acceptance or not of the papers and its publication in the corresponding edition will be decided, as well as the modifications that may be done for its final publication. This notification will be sent by email within 6 months maximum. 


\section{cepoAt edit.um}

